\title{
Evaluation of Dynamic Modulus of HMA Sigmoidal Prediction Models and Optimization by Approach of U.S. Mesh Sieve by AFNOR and LC Mesh Sieve
}

\author{
Mouhamed Lamine Chérif Aidara ${ }^{1}$, Makhaly Ba ${ }^{1}$, Alan Carter ${ }^{2}$ \\ ${ }^{1}$ UFR Sciences de l'Ingénieur, Université de Thiès, Thiès, Sénégal \\ ${ }^{2}$ Ecole de Technologie Supérieure (ETS), Director of Pavement BituminousMaterials Laboratory (LCMB), Montréal, Canada \\ Email: mouhamedlamine.aidara@univ-thies.sn
}

How to cite this paper: Aidara, M.L.C., Ba, M. and Carter, A. (2020) Evaluation of Dynamic Modulus of HMA Sigmoidal Prediction Models and Optimization by Approach of U.S. Mesh Sieve by AFNOR and LC Mesh Sieve. Open Journal of Civil Engineering, 10, 195-212.

https://doi.org/10.4236/ojce.2020.103017

Received: July 3, 2020

Accepted: July 21, 2020

Published: July 24, 2020

Copyright () 2020 by author(s) and Scientific Research Publishing Inc. This work is licensed under the Creative Commons Attribution International License (CC BY 4.0).

http://creativecommons.org/licenses/by/4.0/

\section{(c) (i) Open Access}

\begin{abstract}
Pavement design tools are not universal. Indeed, in the sizing of pavements in the USA, the prediction models used in the calculation of the dynamic modulus of HMA are not adapted to the characterization of the mineral skeleton of the HMA mix designed with the French method. This article aims to assess the predictive models of the dynamic modulus used in the mechanistic-empirical design for their use in the design of bituminous pavements, and to develop new predictive models taking into account the sieve series LC and AFNOR standards. A total of six types of mixtures were subjected to the determination of complex modulus testing by direct tensile-compression on cylindrical specimens (26-700 LC) over a temperature range (5) and frequency (5) data. Dynamic modulus prediction models $\left|E^{*}\right|$ are studied Witczak model 1999 and model Witczak 2006. These models do not take into account the AFNOR or LC mesh sieve, an approach was made in relation to the US mesh sieve to replace $\rho_{200}(0.075 \mathrm{~mm}), \rho_{4}(4.76 \mathrm{~mm}), \rho_{38}(9.5 \mathrm{~mm})$ and $\rho_{34}(19 \mathrm{~mm})$ respectively by the AFNOR mesh $P_{0.08}(0.08 \mathrm{~mm}), R_{5}(5 \mathrm{~mm}), R_{10}(10 \mathrm{~mm})$ and $R_{14}(14 \mathrm{~mm})$. The result is the production of two models whose are evaluated by correlation with the values $\left|E^{*}\right|$ of modulus measured in the laboratory is satisfactory $\left(R^{2}=0.83\right.$ respectively $R^{2}=0.71$ and $p$-value $\left.=0.00\right)$. The optimization of these approximate models gave new models with the same frame as the original models and a better correlation with the data observed in the laboratory (respectively $R^{2}=0.95$ and $R^{2}=0.91 p$-value $=0.00$ ).
\end{abstract}

\section{Keywords}

Dynamic Modulus, Mechanistic-Empirical Design, US, Sieve, Mesh, HMA, AFNOR, LC 


\section{Introduction}

In Mechanistical Empirical Design [1] (Hammons, 2007) the bituminous layer at level 2 and 3 requires the use of prediction model because at level 1 (highest reliability level) the dynamic modulus of Hot Mixture Asphalt (HMA) coatings is determined by laboratory tests [2] [3] [4] [5]. However, when these HMA are mix designed according to the French method with aggregates specified with different sieve mesh, the use of American models is no longer possible. This justifies the need to find a solution. One of the main parameters characterizing the behavior of "Hot Mixture Asphalt" (HMA) in the "Mechanistic-Empirical Pavement Design Guide" (M-EPDG) is the dynamic modulus. However, it has three levels of characterization in this design method. Level 1 is the most accurate, and requires the determination by laboratory tests of the dynamic modulus and Poisson's ratio of each type of mix involved in the pavement structure. The second and third level require the use of a master curve model from a prediction equation developed by the "National Cooperative Highway Research Program" (NCHRP) team [6]. In the dynamic modulus prediction approach for HMA, they exist two main methods. The first is called a discrete finite element method [7] [8] [9]; and a second method using empirical equations [9] [10] or micro prediction equations [9] [11]. The two best-known empirical models are the 1999 Witczak's model and the 2006 Witczak's model. They are characterized by the same parameters except that the viscosity of the binder and the loading frequency directly considered in the 1999 model are replaced by the shear modulus $\left(\left|G^{*}\right|\right)$ and the phase angle of the binder $\left(\delta_{b}\right)$. Parameters related to the granularity of the bituminous mixture in Witczak's empirical models are specified according to US mesh screen (US Standard Series) described by the "American Association of highway and Transportation Official" (AASHTO) standards named $37.5 \mathrm{~mm}, 25.0 \mathrm{~mm}, 19.0 \mathrm{~mm}, 12.5 \mathrm{~mm}, 9.5 \mathrm{~mm}, 4.75 \mathrm{~mm}, 2.36 \mathrm{~mm}, 1.18$ $\mathrm{mm}, 0.60 \mathrm{~mm}, 0.30 \mathrm{~mm}, 0.15 \mathrm{~mm}$ and $0.075 \mathrm{~mm}$. What makes these models almost impossible to use when the sieve mesh from "Canadian Standard Series" (LC) or from French Standards Association (AFNOR) standards are used to learn about the two $14 \mathrm{~mm}, 10 \mathrm{~mm}, 8 \mathrm{~mm}, 5 \mathrm{~mm}, 2.5 \mathrm{~mm}, 1.25 \mathrm{~mm}, 0.315 \mathrm{~mm}$, $0.16 \mathrm{~mm}$ and $0.08 \mathrm{~mm}$. However, a statistical approach remains possible, because Witczak's models are statistical models of sigmoidal type. These models are determined from only database from laboratory tests [4]. In order to make this approach possible similar tests have been carried out.

In this study, the dynamic modulus of asphalt mixtures with aggregate skeletons specified according to AFNOR and Lc sieve are determined by US sieve mesh approach by using the 1999 and 2006 Witczak's models. The aggregates of Senegal used are basalt from Diack and quartzite from Bakel. Bitumen is 35/50 (AFNOR) grade (or pavement grade PG 70/16) ERES.

This article will statistically measure the impact of the approach on the prediction of the dynamic modulus and develop an empirical model whose para- 
meters related to the particle size of the mixture were specified according to Standard French Normalization Association (AFNOR) and Québec Publication (LC) mesh sieve.

\section{Methodology}

The objectives of this paper are to assess the Witczak sigmoidal model prediction of the dynamic modulus for HMA by approaching sieve mesh considered and to develop a new predictive model based on the AFNOR standards sieve mesh and LC by a non-linear optimization in Solver-Microsoft Excel.

A total of six mixtures designed according to the Marshall method and validated according to the level 4 of HMA mix design procedures [12] is studied. Two aggregates types and two nominal maximum aggregate size (NMAS) are used in the different formulation with a single type of bitumen (grade 35/50 ERES or PG70/16). The specimens were cored from asphalt plate compacted to LCPC compactor. They have a height of $125 \mathrm{~mm}$ and a diameter of $74 \mathrm{~mm}$ with a void percentage interval ranging from $2 \%$ to $8 \%$. Direct tension-compression test on cylindrical specimens is used for the measurement of the dynamic modulus mixtures studied. The results of the test on the DSR ERES 35/50 bitumen are used for determining the parameters models related to the asphalt binder (A, VTS, $\eta, \delta_{b}$ and $\left.G^{\star}\right)$.

\subsection{The Test Dynamic Shear Rheometer}

DSR is a test for measuring the rheological stiffness and elasticity binders and bituminous mastics through the dynamic shear modulus $\mathrm{G}^{*}$ and the $\delta$ phase angle [13]. It applies to high temperatures and intermediaries usually an old bitumen from "Rolling Thin Film Oven Test" (RTFOT). To input data requirements for writing prediction models studied, the DSR tests were performed at the same temperature $\left(55^{\circ} \mathrm{C}, 40^{\circ} \mathrm{C}, 30^{\circ} \mathrm{C}, 20^{\circ} \mathrm{C}\right.$ and $\left.10^{\circ} \mathrm{C}\right)$ and frequencies $(10 \mathrm{~Hz}, 5 \mathrm{~Hz}, 1$ $\mathrm{Hz}, 0.3 \mathrm{~Hz}$ and $0.1 \mathrm{~Hz}$ ) than the dynamic modulus is testing.

\subsection{Direct Tension-Compression Test on Cylindrical Specimen}

The complex modulus tests are performed according to standard [13] entitled "Determination of the complex modulus of HMA" by using direct tension-compression equipment (TCD) on cylindrical specimens (Figure 1). $E^{*}$ is determined at small strains, at different frequencies and temperatures, in order to characterize the linear viscoelastic behavior of the mix. $E^{*}$ is a complex number which consists of two parameters, namely the dynamic modulus $\left(\left|E^{*}\right|\right)$, which is the standard of $E^{*}$, and the phase angle $(\delta)$, which is the argument of $E^{*}$. The $\left|E^{*}\right|$ is used for pavement design and $\delta$ can appreciate the viscoelastic behavior of the asphalt.

Figure 2 illustrates the results of a complex modulus test with the offset observed between the stress measurement and those deformations [9].

The complex modulus $E^{*}$ is determined by Equation (1). 

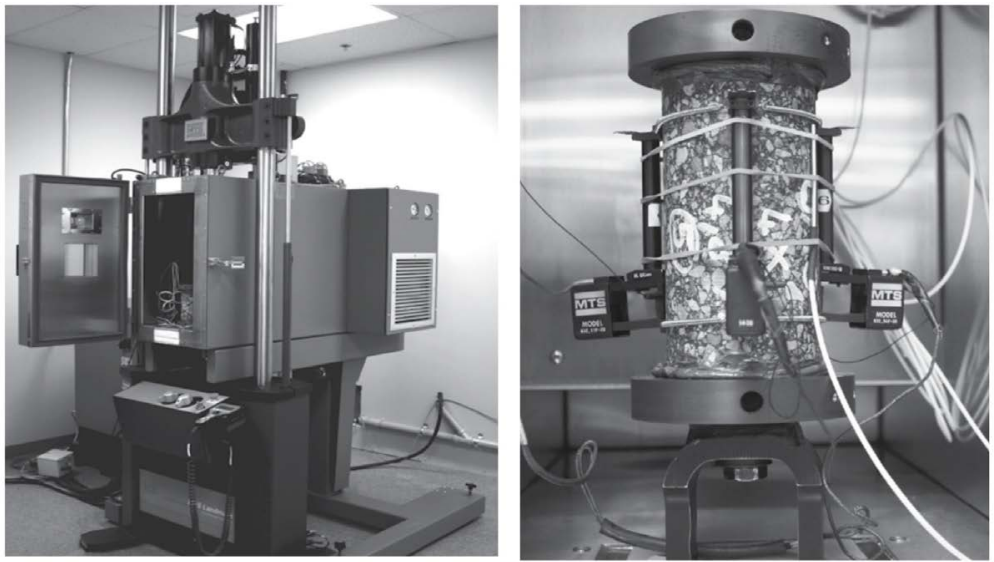

http://www.bitumequebec.ca/wp-content/uploads/2015/03/594ccf2a184885dfile.pdf

Figure 1. HMA specimen on the direct tension-compression equipment [14].

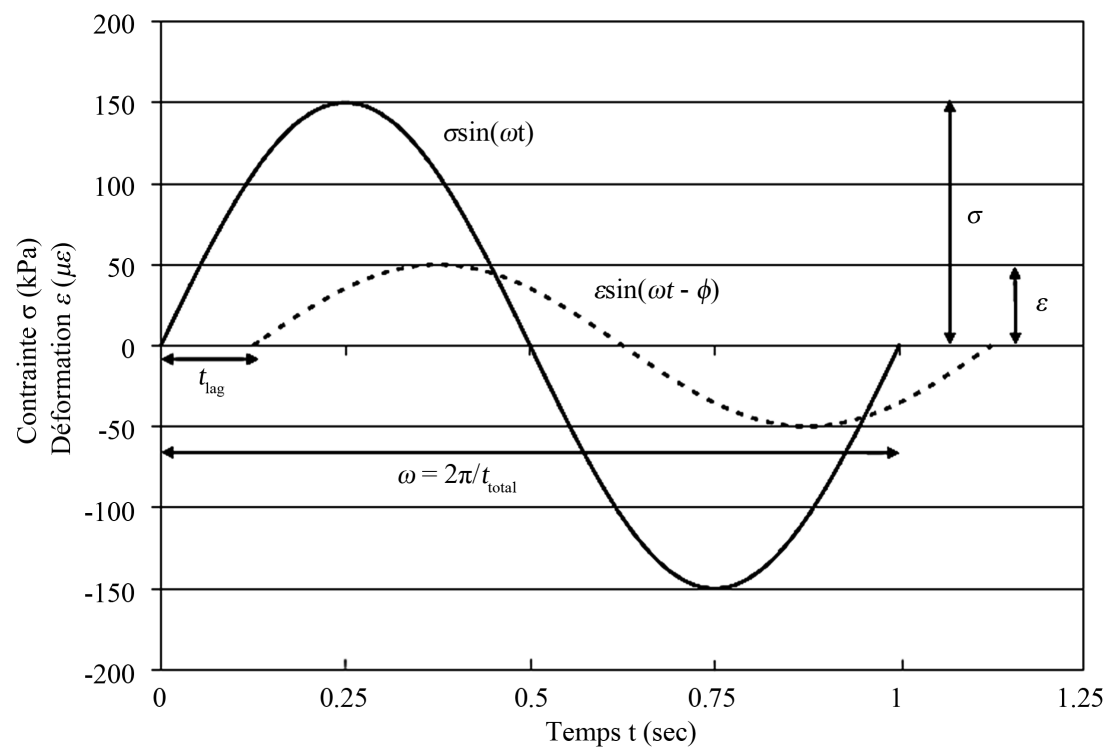

Figure 2. Sinusoidal stress and deformation in tension-compression test [14].

$$
E^{*}=\frac{\sigma \sin (\omega t+\varphi)}{\varepsilon \sin (\omega t-\varphi)}=\left|E^{*}\right| \cos \varphi+i\left|E^{*}\right| \sin \varphi
$$

[14].

Dynamic modulus $\left|E^{*}\right|$ is given by Equation (2) [4]

$$
\left|E^{*}\right|=\frac{\sigma}{\varepsilon}=\frac{4 P / \pi d^{2}}{\delta h / h}
$$

[14].

The phase angle is determined by Equation (3).

$$
\varphi=\omega t_{l \partial g}
$$

(Touhara)

where $E^{*}$ is the complex modulus $(\mathrm{kPa}) ;\left|E^{*}\right|$ is the dynamic modulus $(\mathrm{kPa}) ; \varphi$ is 
the phase angle ( $\mathrm{rad}) ; \sigma$ is the total axial stress $(\mathrm{kPa}) ; \varepsilon$ is the total axial deformation $(\mathrm{m} / \mathrm{m}) ; \omega$ is the period $(2 \cdot \pi \cdot f)(\mathrm{rad}) ; t$ is time $(\mathrm{sec})$; " $P$ " is the imaginary number; $t_{\text {lag }}$ is time to shift between $\mathrm{s}$ and e $(\mathrm{sec}) ; P$ is the axial load $(\mathrm{kN})$; $d$ is the diameter of the test piece (m);. $\Delta h$ is the axial displacement (m); and $h$ : height for measuring. $\Delta h(100 \mathrm{~mm})(\mathrm{m})$.

\subsection{The Model 1999 Witczak's Model}

The 1999 Witczak's model is used in levels 2 and 3 of pavement design. It is given by Equation (4).

$$
\begin{aligned}
& \log \left|E^{*}\right|=-1.249937+0.029232 \rho_{200}-0.001767\left(\rho_{200}\right)^{2}-0.002841 \rho_{4} \\
& -0.058097 V_{a}-0.0802208\left(\frac{V_{\text {beff }}}{V_{\text {beff }}+V_{a}}\right) \\
& +\frac{3.871977-0.0021 \rho_{4}+0.003958 \rho_{38}-0.000017\left(\rho_{38}\right)^{2}+0.005470 \rho_{34}}{1+\mathrm{e}^{(-0.603313-0.31335 \log (f)-0.395321 \log (\eta))}}
\end{aligned}
$$

[4].

With $\left|E^{\star}\right|$ is the dynamic modulus (105 psi); $\eta$ is the viscosity of the binder (106 poise); $f$ is the loading frequency in $\mathrm{Hz} ; \rho_{200}$ is the percentage passing through a sieve $0.075 \mathrm{~mm}$ (No. 200); $\rho_{4}$ cumulative percentage of the sieve 4.76 $\mathrm{mm}$ (No. 4$) ; \rho_{38}$ is the cumulative percentage of the sieve $9.5 \mathrm{~mm}$ ( $\left.3 / 8 \mathrm{in}\right) ; \rho_{34}$ is the cumulative percentage of the sieve, $19 \mathrm{~mm}(3 / 4 \mathrm{in}) ; V_{a}$ is the air void percentage; $V_{\text {beff }}$ is effective binder content in percentage volume.

In fact in the report of NCHRP 1-37A it was developed by recalibration of the dynamic modulus of the prediction model developed by Witczak and Fonseca [10]. It was made by adding a new database to the original database. The evaluation of the reliability of the original model on the original database gave $R^{2}=$ 0.87 precision and Se/Sy 0.36 in basic arithmetic and assessment of its reliability on the new database is less accurate with $R^{2}=0.73$ and Se/Sy $=0.53$. These observed differences assigned to differences in granularity and bitumen in the mixtures of the two databases. The results of the recalibration on the reliability of the model Witczak 1999 was satisfactory with an $R^{2}$ of 0.941 , and Se/Sy 0.2449 [4].

\subsection{The Model Witczak 2006}

However, the 1999 Witczak model poses a problem related to the fact the rigidity of the binder is characterized by a viscosity that does not take into account the effects of the charging frequency. In this model the frequency it is considered as another independent variable entered the predictive equation. However, the viscosity of the binder depends on the charging frequency. Thus changes in the load frequency induce changes of viscosity of the binder. From this point of view the scenario presented by the 1999 model where binder viscosity remains constant when the load frequency changes cannot be conceived in reality. In 2006 Bari and Witczak taking into account remarks cited above set of 7400 modulus 
measurements from 346 mixtures of HMA presents a new model in which the viscosity of the binder and the loading frequency considered directly in the model 1999 are replaced by the shear modulus $\left|G^{*}\right|$ and the phase angle. $\delta_{b}$ of the binder [11]. This model is described by Equation (5)

$$
\begin{aligned}
& \log \left|E^{*}\right|=-0.349+0.754\left(\left|G_{b}^{*}\right|^{-0.0052}\right) \times\left(6.65-0.032 \rho_{200}+\left(0.0027 \rho_{200}\right)^{2}+0.011 \rho_{4}\right. \\
& \left.-0.0001\left(\rho_{4}\right)^{2}+0.006 \rho_{38}-0.00014\left(\rho_{38}\right)^{2}-0.08 V_{a}-0.16\left(\frac{V_{b e f f}}{V_{a}+V_{b e f f}}\right)\right) \\
& +\frac{2.558+0.032 V_{a}+0.713\left(\frac{V_{b e f f}}{V_{a}+V_{b e f f}}\right)+0.0124 \rho_{38}-0.0001\left(\rho_{38}\right)^{2}-0.0098 \rho_{34}}{1+\mathrm{e}^{\left(-0.7814-0.5785 \log \left|G_{b}^{*}\right|+0.8834 \log \delta_{b}\right)}}
\end{aligned}
$$

[11].

where $\left|E^{*}\right|$ is the dynamic modulus (psi); $\left|G^{*}\right|$ is the dynamic shear modulus of the binder; $\delta_{b}$ is the binder phase angle; $\rho_{200}=\%$ of sieving $200 ; \rho_{4}=\%$ cumulative screen oversize $4 ; \rho_{38}=\%$ cumulative screen oversize $3 / 8 ; \rho_{34}=\%$ refusal cumulative $3 / 4$ screen; $V_{a}=\%$ air void; $V_{b e f f}=$ effective binder content.

\subsection{Statistical Interpretations}

The 1999 and 2006 Witczak's models are nonlinear models (polynomial) as a sigmoidal function. Their development was based on the analysis and optimization of the statistical process.

Statistical analysis was intended to reduce the prediction error by comparing the predicted values with the measured values [5].

The nonlinear optimization is to find the values of the regression coefficients or adjustment parameters used in a model so that the model equation has a minimum error when a set of predicted and measured data are compared (Bari and Witczak, 2006).

The goodness of fit indicates the degree of binding of the adjustment parameters to the prediction model. The nonlinear optimization uses as indicator the determination coefficient $R^{2}$ and the ratio of the standard error (Se) and standard deviation (Sy) noted Se/Sy. A good model present a high $R^{2}$ (close to unity) and a low Se/Sy.

Statistical quality of the correlation is given by $R^{2}$ and usually taken $p$-value of $p<0.005$. It is the latter that will be used in the interpretation of our results.

The complex structure of HMA explains the choice of nonlinear optimization to study the predictive models.

The Solver Microsoft Excel is a useful and precise function chosen by most researchers to optimize the nonlinear problems. When the sum of the squared error is minimized, the solution is a biased solution.

The database used to make the calculations are presented as an appendix at the end of the article. 


\subsection{Model Variables}

The analysis of the data consists of 1999 and 2006 Witczak's model parameters i.e. $\left|G^{*}\right|, f, \eta, \delta_{b}, \rho_{200}, \rho_{4}, \rho_{38}, \rho_{34}, V_{a}$ and $V_{\text {beff. }}$ They are the explanatory or independent variables to predict the dependent variable $\log \left|E^{*}\right|$ (explain). However, the values of the sieve meshes are approached $P_{0.08}\left(\rho_{200}\right), R_{10}\left(\rho_{38}\right), R_{14}\left(\rho_{34}\right)$ and $R_{5}\left(\rho_{4}\right)$.

NB: $\eta$ values were determined from the coefficients ASTM A + VTS. This results in Equations (6) and (7) below.

$$
\begin{aligned}
& \log \left|E^{*}\right|=-1.249937+0.029232 P_{0.08}-0.001767\left(P_{0.08}\right)^{2} \\
& -0.002841 R_{5}-0.058097 V_{a}-0.0802208\left(\frac{V_{\text {beff }}}{V_{\text {beff }}+V_{a}}\right) \\
& +\frac{3.871977-0.0021 R_{5}+0.003958 R_{10}-0.000017\left(R_{10}\right)^{2}+0.005470 R_{14}}{1+\mathrm{e}^{(-0.603313-0.31335 \log (f)-0.395321 \log (\eta))}}
\end{aligned}
$$

With $\left|E^{\star}\right|=$ dynamic modulus (105 psi); $\eta=$ viscosity of the binder (106 poise); $f=$ frequency in $\mathrm{Hz}$ loading; $P_{200}=$ percent passing sieve $0.08 \mathrm{~mm} ; R_{5}=$ cumulative percentage of the sieve $5 \mathrm{~mm} ; R_{10}=$ the percentage of cumulative screen oversize $10 \mathrm{~mm} ; R_{14}=$ the percentage of cumulative screen oversize 14 $\mathrm{mm} ; V_{a}=$ percentage of vacuum; $V_{\text {beff }}=$ Binder content effective in percentage volume.

$$
\begin{aligned}
& \log E^{*}=-0.349+0.754\left(\left|G_{b}^{*}\right|^{-0.0052}\right) \times\left(6.65-0.032 P_{0.08}\right. \\
& +\left(0.0027 P_{0.08}\right)^{2}+0.011 R_{5}-0.0001\left(R_{5}\right)^{2}+0.006 R_{10} \\
& \left.-0.00014\left(R_{10}\right)^{2}-0.08 V_{a}-0.16\left(\frac{V_{\text {beff }}}{V_{a}+V_{\text {beff }}}\right)\right) \\
& +\frac{2.558+0.032 V_{a}+0.713\left(\frac{V_{\text {beff }}}{V_{a}+V_{\text {beff }}}\right)+0.0124 R_{10}-0.0001\left(R_{10}\right)^{2}-0.0098 R_{14}}{1+\mathrm{e}^{\left(-0.7814-0.5785 \log \left|G_{b}^{*}\right|+0.8834 \log \delta_{b}\right)}}
\end{aligned}
$$

With $\left|E^{*}\right|=$ dynamic modulus (105 psi); $\left|G^{\star}\right|$ is the dynamic shear modulus of the binder; $\delta_{b}$ is the phase angle of the binder $P_{0.08}=$ percent passing $0.08 \mathrm{~mm}$ sieve; $R_{5}=$ cumulative percentage of the sieve $5 \mathrm{~mm} ; R_{10}=$ the percentage of cumulative screen oversize $10 \mathrm{~mm} ; R_{14}=$ the percentage of cumulative screen oversize $14 \mathrm{~mm} ; V_{a}=$ void percentage; $V_{\text {beff }}=$ Binder content effective in percentage volume.

\section{Results}

\subsection{Evaluation 1999 Witczak's Approached Model}

A correlation is performed on the values of modulus predicted by sieve mesh with the approximate 1999 Witczak's model and the values measured in the laboratory on the mixtures designed with the basalt Diack and the quartzite Bakel 
by direct tensile/compression tests test on cylindrical specimens.

Figure 3 shows a fairly good estimate of the 1999 Witczak's model with a very strong correlation of $R^{2}=0.83$ and a significant $p(p=0.00)$.

\subsection{Adjustment and Optimization of 1999 Witczak's Approached Model}

Table 1 shows the optimized coefficients Witczak module 1999 in comparison to the initial coefficients.

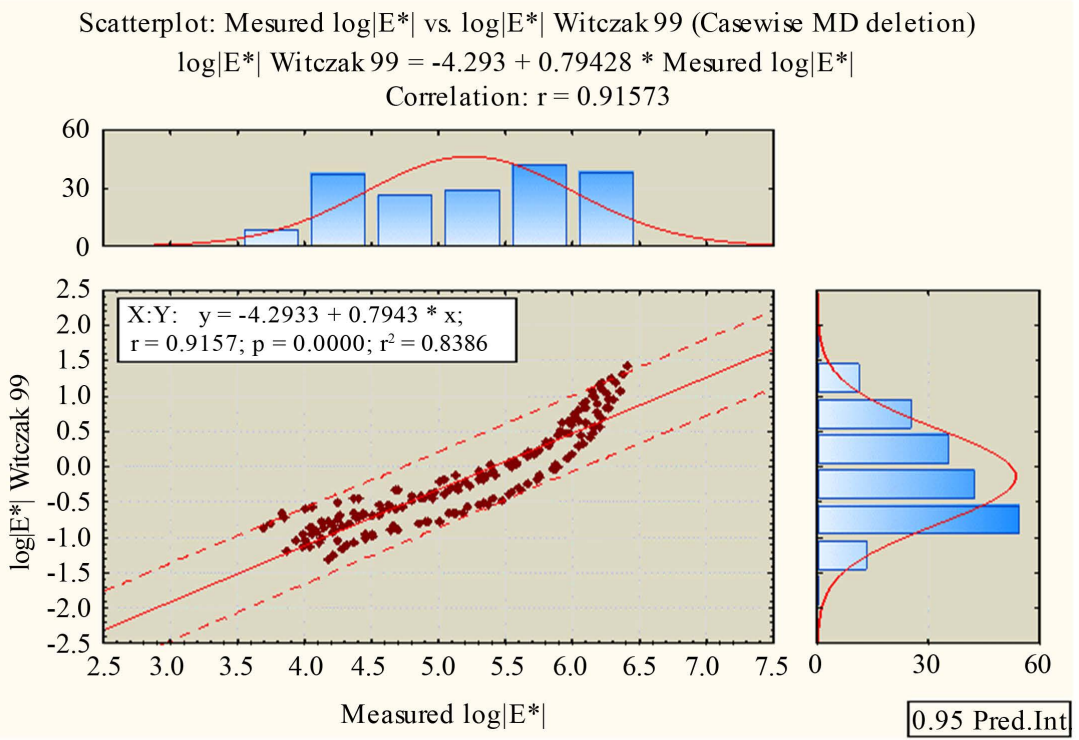

Figure 3. Correlation $p<0.005$ for $\log \left|E^{*}\right|$ and predicted $\log \left|E^{*}\right|$ observed.

Table 1. Comparison of the optimized regression coefficients and the initial coefficients.

\begin{tabular}{ccc}
\hline Régression coefficients & Optimized coefficients & Initial coefficients \\
\hline F1 & 0.152593542 & 1.249937 \\
F2 & 0.006186186 & 0.029232 \\
F3 & 0.003011471 & 0.001767 \\
F5 & 0.002858835 & 0.002841 \\
F6 & 0.0000001 & 0.058097 \\
F7 & 0.088945463 & 0.0802208 \\
F8 & 7.698304773 & 3.871977 \\
F9 & 0.00194078 & 0.0021 \\
F10 & 0.003636243 & 0.003958 \\
F11 & $1.72114 \mathrm{E}-05$ & 0.000017 \\
F12 & 0.003804769 & 0.00547 \\
F13 & 1.90175288 & 0.603313 \\
F14 & 0.205909497 & 0.31335 \\
Sum of squared deviations & 0.284943589 & 0.395321 \\
\hline
\end{tabular}


The new 1999 Witczak's approached model and optimized is given by Equation (8) below:

$$
\begin{aligned}
& \log \left|E^{*}\right|=-0.152593542+0.006186186 P_{0.08}-0.003011471\left(P_{0.08}\right)^{2} \\
& -0.002858835 R_{5}-0.00000017 V_{a}-0.088945463\left(\frac{V_{\text {beff }}}{V_{\text {beff }}+V_{a}}\right) \\
& +\frac{7.698304773-0.00194078 R_{5}+0.003636243 R_{10}-1.72114 E-05\left(R_{10}\right)^{2}+0.003804769 R_{14}}{1+\mathrm{e}^{(-1.90175288-0.205909497 \log (f)-0.2849435891 \log (\eta))}}
\end{aligned}
$$

With $\left|E^{*}\right|=$ dynamic modulus (105 psi); $\eta=$ viscosity of the binder (106 poise); $f=$ frequency in $\mathrm{Hz} ; P_{200}=$ percent passing sieve $0.08 \mathrm{~mm} ; R_{5}=$ cumulative percentage of the sieve $5 \mathrm{~mm} ; R_{10}=$ the percentage of cumulative screen oversize $10 \mathrm{~mm} ; R_{14}=$ the percentage of cumulative screen oversize $14 \mathrm{~mm} ; V_{a}=$ void percentage; $V_{\text {beff }}=$ Binder content effective in percentage volume.

Correlating the predicted modulus values with the new approached model values shows a good correlation with an $R^{2}=0.9574$ and $p=0.00$. Figure 4 illustrate the results of the correlation.

\subsection{Evaluation 2006 Witczak's Approached Model}

A correlation is performed on the values of modulus predicted by sieve mesh with the approximate 2006 Witczak's model and the values measured in the laboratory show a fairly good estimate of the model Witczak 1999 with a very strong correlation of $R^{2}=0.71$ and a significant $p(p=0.00)$ (Figure 5). A non-linear optimization by the MS Excel Solver may however be used to improve the correlation.

\subsection{Adjustment and Optimization of 2006 Witczak's Approached Model}

Table 2 shows the optimized coefficients of 2006 Witczak's model in comparison to the initial coefficients. The optimization shows that the coefficient F11 is

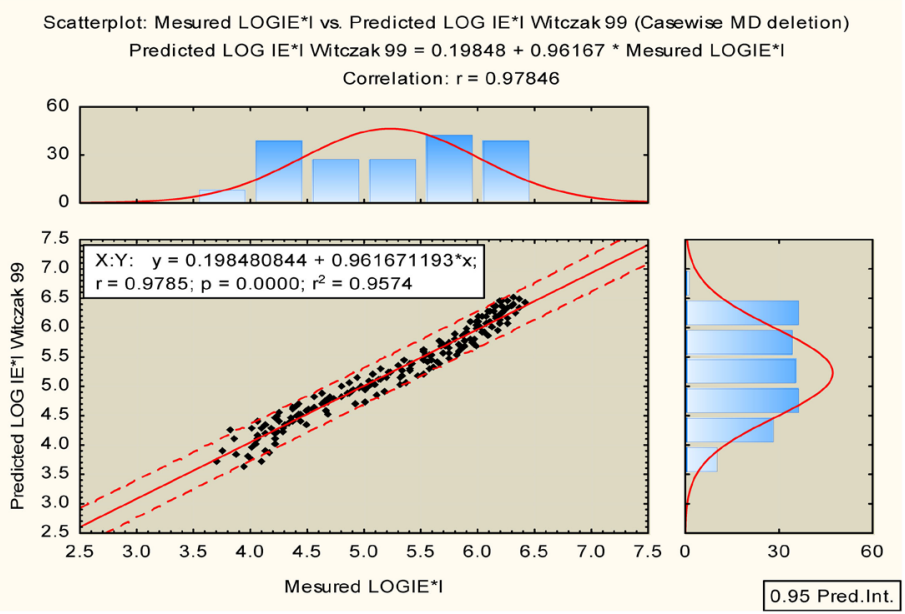

Figure 4. Correlation $p<0.005 \log \left|E^{\star}\right|$ predicted, optimized and $\log \left|E^{\star}\right|$ observed. 
Scatterplot: Mesured logIE*I LOGIE*I Witczak 99 Mesured logIE*I vs. Prédicted LOGIE*| Witczak 06 (Casewise MD deletion)

Prédicted LOGIE*I Witczak $06=3.5737+0.55259$ * Mesured logIE*I LOGIE*I Witczak 99 Mesured $\log \left|E^{*}\right|$

Correlation: $r=0.84365$
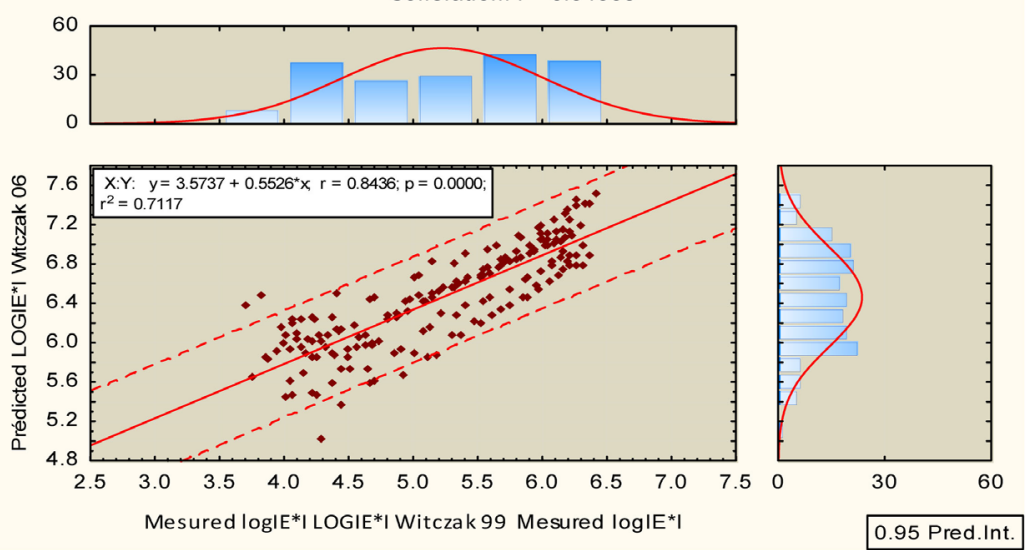

Figure 5. Correlation $p<0.005$ for $\log \left|E^{\star}\right|$ and predicted $\log \left|E^{\star}\right|$ observed.

Table 2. The optimized regression coefficients and the initial coefficients.

\begin{tabular}{ccc}
\hline Régression coefficients & Optimized coefficients & Initial coefficients \\
\hline F1 & 0.354624896 & 0.349 \\
F2 & 0.73016561 & 0.754 \\
F3 & 0.005481779 & 0.0052 \\
F4 & 5.461922604 & 6.65 \\
F5 & 0.036114863 & 0.032 \\
F6 & 0.002060831 & 0.0027 \\
F7 & 0.005137335 & 0.011 \\
F8 & 0.000128808 & 0.0001 \\
F9 & 0.003963945 & 0.006 \\
F10 & 0.000166591 & 0.00014 \\
F11 & 0.0000001 & 0.08 \\
F12 & 0.18414392 & 0.16 \\
F13 & 2.597758994 & 2.558 \\
F14 & 0.040197991 & 0.032 \\
F15 & 0.596946197 & 0.713 \\
F16 & 0.00806974 & 0.012 \\
F17 & 0.000106102 & 0.0001 \\
F18 & 0.010347472 & 0.0098 \\
F19 & 0.847277886 & \\
F20 & 0.80288457 & \\
F21 & 1.540388406 & \\
Sum of squared deviations & & 0.8851 \\
\hline & & \\
\hline
\end{tabular}


canceled by the solver. However, in order to keep the shape intact models, a lower value of this coefficient is chosen so as not to vary the SSD significantly. The new model 2006 Witczak's approached model optimized is given by Equation (9) below.

$$
\begin{aligned}
& \log E^{*}=-0,354624896+0.73016561\left(\left|G_{b}^{*}\right|^{-0.005481779}\right) \\
& \times\left(5.461922604-0.036114863 P_{0.08}+\left(0.002060831 P_{0.08}\right)^{2}+0.005137335 R_{5}\right. \\
& -0.0 .000128808\left(R_{5}\right)^{2}+0.0 .003963945 R_{10}-0.000166591\left(R_{10}\right)^{2} \\
& \left.-0.0000001 V_{a}-0.18414392\left(\frac{V_{\text {beff }}}{V_{a}+V_{\text {beff }}}\right)\right) \\
& +\frac{2.597758994+0.040197991 V_{a}+0.596946197\left(\frac{V_{\text {beff }}}{V_{a}+V_{\text {beff }}}\right)+0.00806974 R_{10}-0.000106102\left(R_{10}\right)^{2}-0.010347472 R_{14}}{1+\mathrm{e}^{\left(-0.847277886-0.80288457 \log \left|G_{b}^{*}\right|+1.540388406 \log \delta_{b}\right)}}
\end{aligned}
$$

With $\left|E^{*}\right|=$ dynamic modulus (105 psi); $\left|G^{*}\right|$ est the dynamic shear modulus of the binder; $\delta_{b}$ is the phase angle of the binder; $P_{0.08}=$ percent passing $0.08 \mathrm{~mm}$ sieve; $R_{5}=$ cumulative percentage of the sieve $5 \mathrm{~mm} ; R_{10}=$ the percentage of cumulative screen oversize $10 \mathrm{~mm} ; R_{14}=$ the percentage of cumulative screen oversize $14 \mathrm{~mm} ; V_{a}=$ void percentage; $V_{\text {beff }}=$ Binder content effective in volume percentage.

Correlating the predicted modulus values with the new model shows a good correlation with an $R^{2}=0.9175$ and $p=0.00$. Figure 6 shows the results of the correlation.

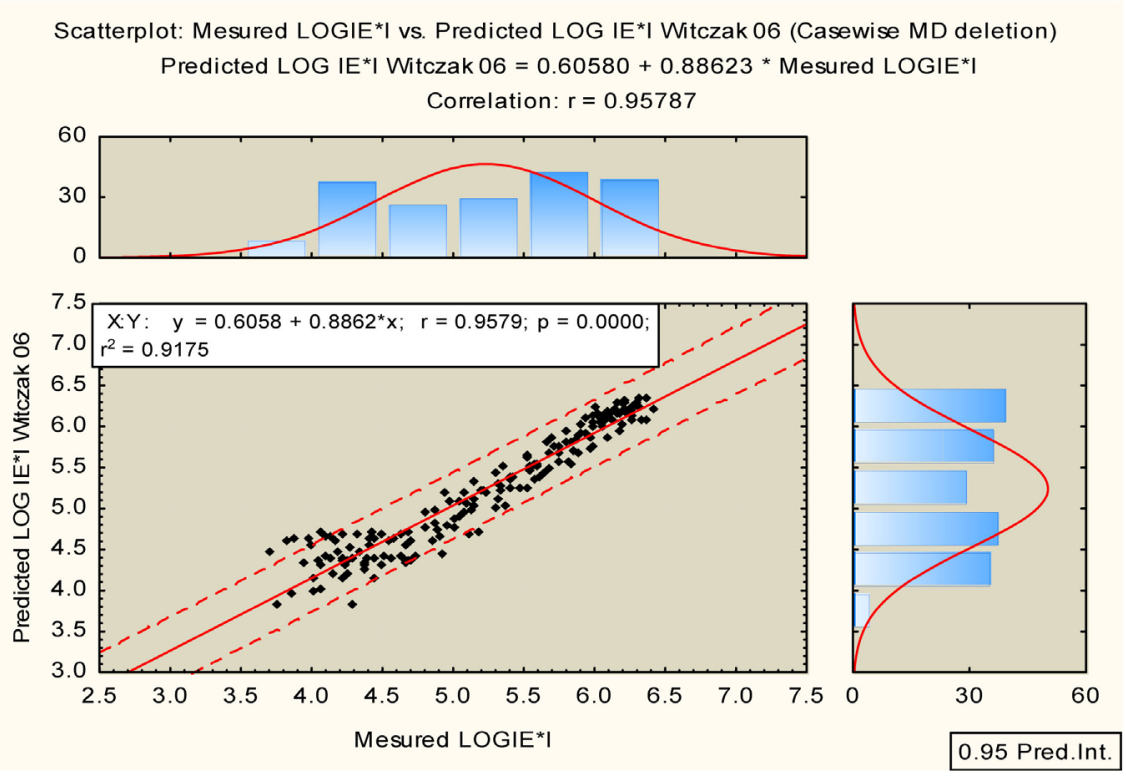

Figure 6. Correlation $p<0.005 \log \left|E^{*}\right|$ predicted, optimized and $\log \left|E^{*}\right|$ observed. 


\section{Conclusion}

The approach of Witczak's sigmoidal model by sieve mesh (1999 and 2006) is a simple replacement of US sieve mesh $\rho_{200}(0.075 \mathrm{~mm}), \rho_{4}(4.76 \mathrm{~mm}), \rho_{38}(9.5$ $\mathrm{mm})$ and $\rho_{34}(19 \mathrm{~mm})$ by AFNOR and Lc sieve mesh respectively $P_{0.08}(0.08$ $\mathrm{mm}), R_{5}(5 \mathrm{~mm}), R_{10}(10 \mathrm{~mm})$ and $R_{14}(14 \mathrm{~mm})$. The evaluation Witczak's model 1999 shows that the sieve mesh approach does not compromise the ability of this model to predict asphalt formulated according to AFNOR and LC methods. The evaluation of the Witczak 2006 model presents a less accurate than the 1999 model. But accuracy remains statistically valid to predict the dynamic modulus of asphalt mixtures. Solver MS-Excel is a great tool adjustment through its nonlinear GRG module. The adjustment of the model approached Witczak 1999 is more accurate than the adjustment of the approximate 2006 model. Dynamic modulus of HMA designed with basalt of Diack and quartzite Diack Bakel is well predicted by Witczak's of 1999 and 2006 model by approached mesh sieve. For best accuracy, however, the optimized models are recommended. In perspective it will be important for a better reliability of the prediction to calibrate these new models with a larger database including different types of HMA.

\section{Acknowledgements}

The authors would like to acknowledge the research group of the "Ecole de Technologies Supérieure" of Montréal.

\section{Conflicts of Interest}

The authors declare no conflicts of interest regarding the publication of this paper.

\section{References}

[1] Hammons, M., Teem, D. and Green, J. (2007) Instrumentation Data Interpretation. State Materials Office, State of Florida.

[2] Li, N., et al. (2020) A Prediction Model of Permanent Strain of Unbound Gravel Materials Based on Performance of Single-Size Gravels under Repeated Loads. Construction and Building Materials, 246, Article ID: 118492. https://doi.org/10.1016/j.conbuildmat.2020.118492

[3] Georgouli, K., Loizos, A. and Plati, C. (2015) Calibration of Dynamic Modulus Predictive Model. Construction and Building Materials, 102, 65-75. https://doi.org/10.1016/j.conbuildmat.2015.10.163

[4] Khattab, A.M., El-Badawy, S.M., Al Hazmi, A.A. and Elmwafi, M. (2014) Evaluation of Witczak $\mathrm{E}^{\star}$ Predictive Models for the Implementation of AASHTOWare-Pavement ME Design in the Kingdom of Saudi Arabia. Construction and Building Materials, 64, 360-369. https://doi.org/10.1016/j.conbuildmat.2014.04.066

[5] AAT (Advanced Asphalt Technologies) (2011) A Manual for Design of Hot Mix Asphalt with Commentary (NCHRP Report 673). National Research Council, Transportation Research Board, Washington DC.

[6] Andrei, D., Mirza, W. and Witczak, W. (1999) Development of a Revised Predictive 
Model for the Dynamic (Complex) Modulus of Asphalt Mixtures. NCHRP Report 1-37A.

[7] You, Z. and Buttlar, W. (2004) Discrete Element Modeling to Predict the Modulus of Asphalt Concrete Mixtures. Journal of Materials in Civil Engineering, 16, 140-146. https://doi.org/10.1061/(ASCE)0899-1561(2004)16:2(140)

[8] You, Z. and Buttlar, W. (2005) Application of Discrete Element Modeling Techniques to Predict the Complex Modulus of Asphalt-Aggregate Hollow Cylinders Subjected to Internal Pressure. Transportation Research Record Journal of the Transportation Research Board, 1929, 218-226. https://doi.org/10.3141/1929-26

[9] You, Z. and Goh, S.W. (2012) Predictive Models for Dynamic Modulus Using Weighted Least Square Nonlinear Multiple Regression Model. Canadian Journal of Civil Engineering, 39, 589-597. https://doi.org/10.1139/12012-035

[10] Bari, J. and Witczak, M.W. (2006) Development of a New Revised Version of the Witczak E* Predictive Model for Hot Mix Asphalt Mixtures. Journal of the Association of Asphalt Paving Technologists, 75, 381-424.

[11] Christensen, D.W., et al. (2003) Hirsch Model for Estimating the Modulus of Asphalt Concrete. Journal of Association of Asphalt Paving Technologists, 72, 97-121.

[12] NFEN 13108-1 (2007) Hot Mixtures Asphalt, Material Specifications Part 1: HMA. French Standards Association (AFNOR).

[13] LC 26-700 (2009) Determination of the Complex Modulus of HMA. Ministry of Transportation Laboratory, Quebec.

[14] Touhara, R. (2012) Etude de la résistance en fatigue des matériaux bitumineux, Mémoire de Maitrise, Ecole de Technologie Supérieure, Montréal Qc. 


\section{Appendix: Data for Statistical Analysis}

\begin{tabular}{|c|c|c|c|c|c|c|c|c|c|c|c|c|c|c|c|c|c|}
\hline \multirow{2}{*}{ 莣 } & \multicolumn{2}{|c|}{$\begin{array}{l}\text { Temperatures } \\
\text { and frequencies }\end{array}$} & \multicolumn{7}{|c|}{ Volumetric composition of mixtures } & \multicolumn{4}{|c|}{ Test on bitumen $35 / 50$ ou PG 70-16 } & \multicolumn{2}{|c|}{$\begin{array}{c}\text { Dynamic } \\
\text { modulus test } \\
\text { laboratory test results }\end{array}$} & \multirow{2}{*}{$\begin{array}{c}\begin{array}{c}\text { Witczak's } \\
1999 \\
\text { model } \\
(\mathrm{MEPDG})\end{array} \\
\\
\\
\text { IE*I } \\
(\mathrm{psi})\end{array}$} & \multirow{2}{*}{$\begin{array}{c}\begin{array}{c}\text { Witczak } \\
2006 \\
\text { model } \\
(M E P D G)\end{array} \\
\\
\\
\mathrm{IE}^{\star} \mathrm{I} \\
(\mathrm{psi})\end{array}$} \\
\hline & $\mathrm{T}^{\circ} \mathrm{C}$ & f. $\mathrm{Hz}$ & $\begin{array}{c}\rho 34- \\
19.00 \\
- \\
14 \\
\mathrm{~mm}\end{array}$ & $\begin{array}{c}\rho 38- \\
9.500 \\
- \\
10 \\
\mathrm{~mm}\end{array}$ & $\begin{array}{c}\rho 4- \\
4.7600 \\
- \\
5 \\
\mathrm{~mm}\end{array}$ & $\begin{array}{c}\rho 200- \\
0.075 \\
- \\
0.08 \\
\mathrm{~mm}\end{array}$ & $V_{\text {beff }}$ & $\mathrm{Va}$ & A & $\begin{array}{c}\text { Viscosity } \\
\eta\left(10^{6} \mathrm{~Pa} . \mathrm{s}\right)\end{array}$ & VTS & $\delta \mathrm{b}\left(\left(^{\circ}\right)\right.$ & $\begin{array}{c}\text { Module } \\
\text { Dynamic } \\
\text { Modulus } \\
\text { (DSR test) } \\
\text { (psi) }\end{array}$ & $\mathrm{IE}^{\star} \mathrm{I}(\mathrm{psi})$ & $\delta\left(\left(^{\circ}\right)\right.$ & & \\
\hline BDF & -0.11484506 & 10.0472826 & 1 & 8 & 28 & 8 & 11.34 & 8.77 & 14.2392 & 2.08163462 & -4.9303 & 3.64441901 & 916.182811 & $2,291,337.61$ & 7.45477925 & $1,210,297.381$ & $7,668,937.03$ \\
\hline BDF & -0.17177768 & 3.01465895 & 1 & 8 & 28 & 8 & 11.34 & 8.77 & 14.2392 & 2.12809128 & -4.9303 & 6.86064288 & 866.262618 & $2,063,567.16$ & 8.33227858 & $911,503.2797$ & $6,147,775.18$ \\
\hline BDF & -0.16600072 & 1.00487491 & 1 & 8 & 28 & 8 & 11.34 & 8.77 & 14.2392 & 2.12332779 & -4.9303 & 6.51793241 & 794.210857 & $1,859,340.45$ & 9.20601144 & $686,683.8367$ & $6,163,390.03$ \\
\hline BDF & -0.13361162 & 0.30146788 & 1 & 8 & 28 & 8 & 11.34 & 8.77 & 14.2392 & 2.09682854 & -4.9303 & 6.22597098 & 652.178106 & $1,631,950.11$ & 10.4005233 & $492,989.5483$ & $6,038,348.22$ \\
\hline BDF & -0.15027567 & 0.10048827 & 1 & 8 & 28 & 8 & 11.34 & 8.77 & 14.2392 & 2.11041839 & -4.9303 & 6.84430949 & 577.603468 & $1,454,126.46$ & 11.0535909 & $361,762.2698$ & $5,683,056.22$ \\
\hline BDF & 10.0207844 & 10.0532669 & 1 & 8 & 28 & 8 & 11.34 & 8.77 & 14.2392 & 0.06104662 & -4.9303 & 5.0917143 & 814.556336 & $1,574,781.67$ & 11.6630179 & $376,195.2083$ & $6,758,109.04$ \\
\hline BDF & 9.94728906 & 3.01594813 & 1 & 8 & 28 & 8 & 11.34 & 8.77 & 14.2392 & 0.06246433 & -4.9303 & 11.1561055 & 750.623093 & $1,346,510.71$ & 13.0939069 & $266,943.4389$ & $4,921,449.26$ \\
\hline BDF & 9.93841748 & 1.00452044 & 1 & 8 & 28 & 8 & 11.34 & 8.77 & 14.2392 & 0.06263782 & -4.9303 & 14.3708818 & 678.714916 & $1,133,489.39$ & 14.6918064 & $192,501.261$ & $4,293,957.74$ \\
\hline BDF & 9.98368722 & 0.30144998 & 1 & 8 & 28 & 8 & 11.34 & 8.77 & 14.2392 & 0.06175788 & -4.9303 & 19.4496154 & 575.887026 & $927,669.744$ & 16.5705198 & $133,242.3532$ & $3,552,076.94$ \\
\hline BDF & 9.9725091 & 0.10038991 & 1 & 8 & 28 & 8 & 11.34 & 8.77 & 14.2392 & 0.06197392 & -4.9303 & 27.262347 & 495.559167 & $762,551.562$ & 18.1700157 & $95,883.74145$ & $2,842,367.47$ \\
\hline BDF & 19.9685955 & 10.0535104 & 1 & 8 & 28 & 8 & 11.34 & 8.77 & 14.2392 & 0.00368965 & -4.9303 & 17.4031234 & 601.52195 & $913,646.296$ & 18.4030165 & $131,339.9082$ & $3,799,350.87$ \\
\hline BDF & 19.9655083 & 3.01204819 & 1 & 8 & 28 & 8 & 11.34 & 8.77 & 14.2392 & 0.00369255 & -4.9303 & 25.7093848 & 486.139494 & $711,357.672$ & 20.6203447 & $91,495.3866$ & $2,918,216.43$ \\
\hline BDF & 19.9582191 & 1.00466551 & 1 & 8 & 28 & 8 & 11.34 & 8.77 & 14.2392 & 0.0036994 & -4.9303 & 30.8371738 & 375.165254 & $553,920.83$ & 22.6034087 & $66,193.19964$ & $2,423,984.35$ \\
\hline BDF & 19.9278062 & 0.30141668 & 1 & 8 & 28 & 8 & 11.34 & 8.77 & 14.2392 & 0.00372814 & -4.9303 & 36.4035093 & 263.912773 & $405,880.599$ & 25.4169001 & $46,966.73523$ & $1,943,056.15$ \\
\hline BDF & 19.9606592 & 0.10049039 & 1 & 8 & 28 & 8 & 11.34 & 8.77 & 14.2392 & 0.00369711 & -4.9303 & 44.3154074 & 227.583289 & $294,956.589$ & 27.9473783 & $34,574.52292$ & $1,624,261.99$ \\
\hline BDF & 29.8351333 & 10.0598564 & 1 & 8 & 28 & 8 & 11.34 & 8.77 & 14.2392 & 0.00037844 & -4.9303 & 35.0014984 & 350.953452 & $468,929.188$ & 25.9965025 & $56,070.53311$ & $2,198,746.19$ \\
\hline BDF & 29.8489495 & 3.01987169 & 1 & 8 & 28 & 8 & 11.34 & 8.77 & 14.2392 & 0.00037735 & -4.9303 & 44.2050338 & 225.289547 & $330,752.087$ & 28.8285446 & $39,890.09239$ & $1,620,743.91$ \\
\hline BDF & 29.8387026 & 1.00524211 & 1 & 8 & 28 & 8 & 11.34 & 8.77 & 14.2392 & 0.00037816 & -4.9303 & 50.2280149 & 126.986387 & $232,716.584$ & 31.7376712 & $29,674.1178$ & $1,191,791.37$ \\
\hline BDF & 29.8588742 & 0.30153569 & 1 & 8 & 28 & 8 & 11.34 & 8.77 & 14.2392 & 0.00037657 & -4.9303 & 53.6978965 & 44.469069 & $151,795.713$ & 34.2194037 & $21,803.47975$ & $737,107.16$ \\
\hline BDF & 29.816896 & 0.10040112 & 1 & 8 & 28 & 8 & 11.34 & 8.77 & 14.2392 & 0.00037989 & -4.9303 & 58.1311473 & 61.7935544 & $100,876.494$ & 36.6690388 & $16,818.27282$ & $799,711.56$ \\
\hline BDF & 39.5592949 & 10.0205943 & 1 & 8 & 28 & 8 & 11.34 & 8.77 & 14.2392 & $5.9361 \mathrm{E}-05$ & -4.9303 & 52.5313381 & 134.527441 & $202,490.281$ & 34.5227993 & $29,389.83066$ & $1,182,523.87$ \\
\hline BDF & 39.5699807 & 3.01664778 & 1 & 8 & 28 & 8 & 11.34 & 8.77 & 14.2392 & $5.9252 \mathrm{E}-05$ & -4.9303 & 60.7607668 & 53.6936408 & $129,050.987$ & 36.9966681 & $21,642.65707$ & $729,965.04$ \\
\hline BDF & 39.5983539 & 1.00401606 & 1 & 8 & 28 & 8 & 11.34 & 8.77 & 14.2392 & $5.8961 \mathrm{E}-05$ & -4.9303 & 67.3392148 & 23.8125803 & $82,779.9231$ & 38.9739953 & $16,634.58617$ & $478,380.98$ \\
\hline BDF & 39.5774447 & 0.30154867 & 1 & 8 & 28 & 8 & 11.34 & 8.77 & 14.2392 & $5.9175 \mathrm{E}-05$ & -4.9303 & 67.5823376 & 16.3906146 & $49,436.5059$ & 41.0739191 & $12,774.83761$ & $406,621.28$ \\
\hline BDF & 39.5739282 & 0.10048905 & 1 & 8 & 28 & 8 & 11.34 & 8.77 & 14.2392 & $5.9211 \mathrm{E}-05$ & -4.9303 & 68.8607733 & 67.1369536 & $31,676.902$ & 41.7565005 & $10,229.97225$ & $732,834.74$ \\
\hline BDF & 54.0749205 & 10.0539698 & 1 & 8 & 28 & 8 & 11.34 & 8.77 & 14.2392 & $6.5562 \mathrm{E}-06$ & -4.9303 & 68.2407958 & 14.5601578 & $46,675.4254$ & 43.7014272 & $14,968.101$ & $383,874.96$ \\
\hline BDF & 54.0638944 & 3.01204819 & 1 & 8 & 28 & 8 & 11.34 & 8.77 & 14.2392 & $6.5658 \mathrm{E}-06$ & -4.9303 & 70.464758 & 4.87522601 & $27,958.8655$ & 43.3037334 & $11,583.59064$ & $237,769.44$ \\
\hline BDF & 54.0698369 & 1.00654507 & 1 & 8 & 28 & 8 & 11.34 & 8.77 & 14.2392 & $6.5607 \mathrm{E}-06$ & -4.9303 & 78.2094929 & 9.56044226 & $17,558.5413$ & 42.1049774 & 9354.020612 & $291,313.65$ \\
\hline BDF & 54.0932081 & 0.30143836 & 1 & 8 & 28 & 8 & 11.34 & 8.77 & 14.2392 & $6.5404 \mathrm{E}-06$ & -4.9303 & 75.5092721 & 19.6687803 & $11,009.1005$ & 40.1422943 & 7552.722807 & $405,333.50$ \\
\hline BDF & 54.0770426 & 0.10049242 & 1 & 8 & 28 & 8 & 11.34 & 8.77 & 14.2392 & $6.5544 \mathrm{E}-06$ & -4.9303 & 79.3911228 & 74.4823983 & 7456.42731 & 37.9602201 & 6342.891285 & $690,724.08$ \\
\hline BDC & 0.14847441 & 10.0503147 & 3 & 17 & 50 & 4 & 11 & 8.91 & 14.2392 & 1.88028298 & -4.9303 & 3.49393748 & 915.646643 & $2,045,179.08$ & 7.71949902 & $923,709.1634$ & $9,825,318.98$ \\
\hline BDC & 0.21004821 & 3.01568813 & 3 & 17 & 50 & 4 & 11 & 8.91 & 14.2392 & 1.83623549 & -4.9303 & 6.75944172 & 867.017156 & $1,825,803.45$ & 9.12726814 & $684,308.6439$ & $7,787,845.95$ \\
\hline
\end{tabular}




\section{Continued}

\begin{tabular}{|c|c|c|c|c|c|c|c|c|c|c|c|c|c|c|c|c|c|}
\hline BDC & 0.22865472 & 1.00468869 & 3 & 17 & 50 & 4 & 11 & 8.91 & 14.2392 & 1.8231406 & -4.9303 & 6.59166808 & 797.644449 & $1,616,159.99$ & 10.5100648 & $513,338.5739$ & $7,737,295.00$ \\
\hline BDC & 0.11403329 & 0.30146816 & 3 & 17 & 50 & 4 & 11 & 8.91 & 14.2392 & 1.90540632 & -4.9303 & 6.47211826 & 657.261173 & $1,390,057.49$ & 12.6732943 & $375,117.3644$ & $7,502,155.78$ \\
\hline BDC & 0.16946427 & 0.10049241 & 3 & 17 & 50 & 4 & 11 & 8.91 & 14.2392 & 1.86514357 & -4.9303 & 7.53750712 & 582.523183 & $1,169,179.64$ & 15.2937661 & $272,232.9953$ & $6,885,564.56$ \\
\hline BDC & 9.78889979 & 10.0390843 & 3 & 17 & 50 & 4 & 11 & 8.91 & 14.2392 & 0.06564045 & -4.9303 & 4.91237237 & 818.469453 & $1,431,374.72$ & 12.5607237 & $303,883.5695$ & $8,641,122.01$ \\
\hline BDC & 9.79486882 & 3.0090286 & 3 & 17 & 50 & 4 & 11 & 8.91 & 14.2392 & 0.06551769 & -4.9303 & 10.9983893 & 753.953225 & $1,198,326.53$ & 14.9458392 & $213,818.9229$ & $6,217,730.04$ \\
\hline BDC & 9.80409112 & 1.00563219 & 3 & 17 & 50 & 4 & 11 & 8.91 & 14.2392 & 0.06532849 & -4.9303 & 14.1966027 & 682.21095 & $974,972.666$ & 18.0977192 & $154,104.5678$ & $5,410,199.77$ \\
\hline BDC & 9.84189095 & 0.30145 & 3 & 17 & 50 & 4 & 11 & 8.91 & 14.2392 & 0.06455908 & -4.9303 & 19.2276692 & 579.696301 & $746,183.538$ & 22.1841617 & $106,765.6642$ & $4,462,963.10$ \\
\hline BDC & 9.7986725 & 0.10040866 & 3 & 17 & 50 & 4 & 11 & 8.91 & 14.2392 & 0.06543958 & -4.9303 & 26.9383462 & 499.730369 & $563,614.751$ & 26.3104645 & $77,139.11068$ & $3,562,050.60$ \\
\hline BDC & 20.3069283 & 10.0307091 & 3 & 17 & 50 & 4 & 11 & 8.91 & 14.2392 & 0.00338642 & -4.9303 & 17.9475929 & 593.17194 & $770,765.346$ & 22.2695279 & $100,098.7775$ & $4,651,964.37$ \\
\hline BDC & 20.3149364 & 3.01204819 & 3 & 17 & 50 & 4 & 11 & 8.91 & 14.2392 & 0.00337958 & -4.9303 & 26.3277482 & 476.233469 & $561,682.715$ & 26.9193824 & $69,753.40627$ & $3,553,905.58$ \\
\hline BDC & 20.3032369 & 1.00401606 & 3 & 17 & 50 & 4 & 11 & 8.91 & 14.2392 & 0.00338958 & -4.9303 & 31.4922101 & 364.698454 & $394,639.958$ & 31.6006444 & $50,525.1017$ & $2,934,873.92$ \\
\hline BDC & 20.1520879 & 0.30151622 & 3 & 17 & 50 & 4 & 11 & 8.91 & 14.2392 & 0.00352172 & -4.9303 & 36.8033643 & 257.148228 & $254,642.036$ & 36.6166016 & $36,301.44258$ & $2,356,369.16$ \\
\hline BDC & 20.0650168 & 0.10049241 & 3 & 17 & 50 & 4 & 11 & 8.91 & 14.2392 & 0.00360035 & -4.9303 & 44.4773605 & 225.005717 & $162,722.946$ & 40.4786334 & $27,029.51798$ & $1,982,201.78$ \\
\hline BDC & 30.1979938 & 10.020902 & 3 & 17 & 50 & 4 & 11 & 8.91 & 14.2392 & 0.0003509 & -4.9303 & 35.6835974 & 341.908295 & $351,143.561$ & 34.2606021 & $42,970.9345$ & $2,660,345.60$ \\
\hline BDC & 30.158609 & 3.01034967 & 3 & 17 & 50 & 4 & 11 & 8.91 & 14.2392 & 0.00035378 & -4.9303 & 44.7871336 & 218.224544 & $219,672.376$ & 38.8499103 & $30,739.66175$ & $1,950,160.86$ \\
\hline BDC & 30.2015492 & 1.00806452 & 3 & 17 & 50 & 4 & 11 & 8.91 & 14.2392 & 0.00035064 & -4.9303 & 50.931944 & 120.481397 & $136,349.56$ & 41.8356226 & $22,850.85775$ & $1,411,135.37$ \\
\hline BDC & 30.2004703 & 0.30146215 & 3 & 17 & 50 & 4 & 11 & 8.91 & 14.2392 & 0.00035072 & -4.9303 & 54.2566499 & 40.4181942 & $79,760.5141$ & 42.4319329 & $16,830.86172$ & $849,828.59$ \\
\hline BDC & 30.198284 & 0.10038392 & 3 & 17 & 50 & 4 & 11 & 8.91 & 14.2392 & 0.00035088 & -4.9303 & 58.6056193 & 59.0172814 & $48,993.242$ & 40.9098628 & $12,973.57781$ & $945,104.28$ \\
\hline BDC & 40.4573195 & 10.0891469 & 3 & 17 & 50 & 4 & 11 & 8.91 & 14.2392 & $5.0873 \mathrm{E}-05$ & -4.9303 & 53.9836022 & 118.458554 & $121,083.63$ & 44.0927827 & $22,078.19975$ & $1,344,961.98$ \\
\hline BDC & 40.5204679 & 3.02121729 & 3 & 17 & 50 & 4 & 11 & 8.91 & 14.2392 & $5.0329 \mathrm{E}-05$ & -4.9303 & 62.0839614 & 43.0107125 & $70,191.5343$ & 43.5470032 & $16,248.10298$ & $790,005.86$ \\
\hline BDC & 40.5161152 & 1.00401606 & 3 & 17 & 50 & 4 & 11 & 8.91 & 14.2392 & $5.0367 \mathrm{E}-05$ & -4.9303 & 68.6625614 & 20.9589774 & $43,844.1825$ & 40.2142615 & $12,549.44311$ & $535,556.71$ \\
\hline BDC & 40.4982977 & 0.30146215 & 3 & 17 & 50 & 4 & 11 & 8.91 & 14.2392 & $5.052 \mathrm{E}-05$ & -4.9303 & 68.6210342 & 20.9147106 & $28,102.9495$ & 34.7538524 & 9673.594195 & $535,304.54$ \\
\hline BDC & 40.5051726 & 0.10049949 & 3 & 17 & 50 & 4 & 11 & 8.91 & 14.2392 & $5.046 \mathrm{E}-05$ & -4.9303 & 69.731563 & 73.589921 & $20,620.8874$ & 29.4538585 & 7772.176219 & $914,371.64$ \\
\hline BDC & 55.3654519 & 10.0877193 & 3 & 17 & 50 & 4 & 11 & 8.91 & 14.2392 & $5.5374 \mathrm{E}-06$ & -4.9303 & 68.56248 & 22.0357368 & $32,392.4092$ & 37.7332386 & $11,282.34065$ & $547,990.63$ \\
\hline BDC & 55.3539165 & 3.01738063 & 3 & 17 & 50 & 4 & 11 & 8.91 & 14.2392 & $5.5456 \mathrm{E}-06$ & -4.9303 & 69.9400416 & 10.2297404 & $23,478.4085$ & 29.1051442 & 8765.213903 & $387,210.21$ \\
\hline BDC & 55.4172026 & 1.00937588 & 3 & 17 & 50 & 4 & 11 & 8.91 & 14.2392 & $5.5004 \mathrm{E}-06$ & -4.9303 & 77.8494551 & 0.37554088 & $19,332.5449$ & 22.4188032 & 7094.582416 & $104,246.70$ \\
\hline BDC & 55.3401578 & 0.30150769 & 3 & 17 & 50 & 4 & 11 & 8.91 & 14.2392 & $5.5555 \mathrm{E}-06$ & -4.9303 & 75.1739137 & 6.89990411 & $16,476.8457$ & 17.6326354 & 5766.110804 & $310,914.57$ \\
\hline BDC & 54.4 & 0.1 & 3 & 17 & 50 & 4 & 11 & 8.91 & 14.2392 & $6.2808 \mathrm{E}-06$ & -4.9303 & 79.551876 & 68.0027194 & 14,935 & 14.7 & 4967.126873 & $801,751.44$ \\
\hline GDF & 0.91366976 & 10.0493043 & 2 & 10 & 26 & 10 & 11.64 & 5.28 & 14.2392 & 1.40364346 & -4.9303 & 3.12003647 & 913.363935 & $1,945,855.5$ & 8.32604637 & $1,728,227.122$ & $15,815,706.76$ \\
\hline GDF & 0.9604202 & 3.01481783 & 2 & 10 & 26 & 10 & 11.64 & 5.28 & 14.2392 & 1.37901074 & -4.9303 & 6.62835593 & 867.050268 & $1,669,844.61$ & 9.29360797 & $1,272,353.469$ & $12,279,368.28$ \\
\hline GDF & 0.93101915 & 1.00493928 & 2 & 10 & 26 & 10 & 11.64 & 5.28 & 14.2392 & 1.39444825 & -4.9303 & 6.7759871 & 801.679463 & $1,485,114.91$ & 11.0193887 & $954,192.7483$ & $12,003,460.14$ \\
\hline GDF & 0.93807777 & 0.30147519 & 2 & 10 & 26 & 10 & 11.64 & 5.28 & 14.2392 & 1.39072541 & -4.9303 & 7.32398628 & 670.851515 & $1,270,227.34$ & 13.201413 & $681,530.8249$ & $11,254,539.54$ \\
\hline GDF & 0.94223131 & 0.10049233 & 2 & 10 & 26 & 10 & 11.64 & 5.28 & 14.2392 & 1.38853968 & -4.9303 & 9.19986803 & 591.698044 & $1,077,091.84$ & 15.5804412 & $495,486.2977$ & $9,989,999.96$ \\
\hline GDF & 12.7895703 & 10.0431208 & 2 & 10 & 26 & 10 & 11.64 & 5.28 & 14.2392 & 0.02636181 & -4.9303 & 7.66565294 & 763.39781 & $1,108,988.73$ & 16.3915186 & $440,749.2547$ & $11,348,915.60$ \\
\hline GDF & 12.7479521 & 3.01508147 & 2 & 10 & 26 & 10 & 11.64 & 5.28 & 14.2392 & 0.02668719 & -4.9303 & 14.4536316 & 684.148111 & $876,714.196$ & 19.3984558 & $308,876.2275$ & $8,473,684.44$ \\
\hline GDF & 12.753971 & 1.00502513 & 2 & 10 & 26 & 10 & 11.64 & 5.28 & 14.2392 & 0.02663987 & -4.9303 & 18.3606831 & 599.30268 & $677,466.802$ & 22.5528796 & $221,394.9542$ & $7,303,360.58$ \\
\hline GDF & 12.7208499 & 0.3014621 & 2 & 10 & 26 & 10 & 11.64 & 5.28 & 14.2392 & 0.02690139 & -4.9303 & 23.8771513 & 495.310836 & $486,410.468$ & 27.1133126 & $154,482.0938$ & $6,039,873.02$ \\
\hline
\end{tabular}




\section{Continued}

\begin{tabular}{|c|c|c|c|c|c|c|c|c|c|c|c|c|c|c|c|c|c|}
\hline GDF & 12.7771036 & 0.10040868 & 2 & 10 & 26 & 10 & 11.64 & 5.28 & 14.2392 & 0.02645883 & -4.9303 & 32.3609763 & 422.683701 & $341,894.876$ & 31.4825821 & $110,659.354$ & $4,850,267.29$ \\
\hline GDF & 22.1228003 & 10.0393271 & 2 & 10 & 26 & 10 & 11.64 & 5.28 & 14.2392 & 0.00215842 & -4.9303 & 20.9685642 & 547.693688 & $564,580.228$ & 26.2727187 & $170,246.3942$ & $6,660,090.94$ \\
\hline GDF & 22.1313662 & 3.01813314 & 2 & 10 & 26 & 10 & 11.64 & 5.28 & 14.2392 & 0.00215392 & -4.9303 & 29.6145232 & 425.037238 & $387,217.28$ & 30.793245 & $118,742.884$ & $5,112,828.35$ \\
\hline GDF & 22.1411563 & 1.00477362 & 2 & 10 & 26 & 10 & 11.64 & 5.28 & 14.2392 & 0.00214879 & -4.9303 & 35.0363219 & 310.506437 & $257,364.896$ & 35.315075 & $86,019.94632$ & $4,169,996.98$ \\
\hline GDF & 22.1161199 & 0.30154219 & 2 & 10 & 26 & 10 & 11.64 & 5.28 & 14.2392 & 0.00216193 & -4.9303 & 40.3065339 & 200.675767 & $155,728.296$ & 39.2201889 & $61,374.43035$ & $3,264,781.55$ \\
\hline GDF & 22.1598994 & 0.10049241 & 2 & 10 & 26 & 10 & 11.64 & 5.28 & 14.2392 & 0.00213901 & -4.9303 & 47.6574683 & 176.303525 & $95,513.9453$ & 41.495881 & $45,478.72847$ & $2,785,004.04$ \\
\hline GDF & 32.5854758 & 10.0540723 & 2 & 10 & 26 & 10 & 11.64 & 5.28 & 14.2392 & 0.00021624 & -4.9303 & 40.1586964 & 283.708234 & $211,805.518$ & 38.8314608 & $72,616.50844$ & $3,713,730.78$ \\
\hline GDF & 32.6482355 & 3.01813314 & 2 & 10 & 26 & 10 & 11.64 & 5.28 & 14.2392 & 0.00021357 & -4.9303 & 49.3845244 & 164.909778 & $122,813.913$ & 41.8576285 & $51,878.13052$ & $2,649,983.96$ \\
\hline GDF & 32.6268499 & 1.00446499 & 2 & 10 & 26 & 10 & 11.64 & 5.28 & 14.2392 & 0.00021448 & -4.9303 & 55.5451048 & 82.4570629 & $74,824.2659$ & 42.6619687 & $38,948.93662$ & $1,849,469.02$ \\
\hline GDF & 32.6366237 & 0.30149673 & 2 & 10 & 26 & 10 & 11.64 & 5.28 & 14.2392 & 0.00021406 & -4.9303 & 58.1202504 & 18.6672783 & $42,479.5676$ & 41.4253257 & $28,954.75292$ & $954,758.69$ \\
\hline GDF & 32.6139912 & 0.10049241 & 2 & 10 & 26 & 10 & 11.64 & 5.28 & 14.2392 & 0.00021502 & -4.9303 & 61.5068619 & 47.8309001 & $27,132.6836$ & 38.2839747 & $22,550.93461$ & $1,368,580.26$ \\
\hline GDF & 43.121377 & 10.0733295 & 2 & 10 & 26 & 10 & 11.64 & 5.28 & 14.2392 & $3.2677 \mathrm{E}-05$ & -4.9303 & 58.0126297 & 76.2281762 & $63,524.8626$ & 45.4567504 & $38,279.00358$ & $1,735,928.15$ \\
\hline GDF & 43.1134247 & 3.01204819 & 2 & 10 & 26 & 10 & 11.64 & 5.28 & 14.2392 & $3.2719 \mathrm{E}-05$ & -4.9303 & 65.3040681 & 19.6163769 & $36,780.7312$ & 42.3334864 & $28,492.43059$ & $895,663.56$ \\
\hline GDF & 43.1553698 & 1.00654635 & 2 & 10 & 26 & 10 & 11.64 & 5.28 & 14.2392 & $3.2497 \mathrm{E}-05$ & -4.9303 & 72.0819351 & 17.3302903 & $23,168.9483$ & 37.6760989 & $22,159.70932$ & $790,597.87$ \\
\hline GDF & 43.1365971 & 0.30152269 & 2 & 10 & 26 & 10 & 11.64 & 5.28 & 14.2392 & $3.2596 \mathrm{E}-05$ & -4.9303 & 71.2567835 & 36.5200794 & $15,307.1721$ & 30.6543858 & $17,228.26284$ & $1,096,150.66$ \\
\hline GDF & 43.1298645 & 0.10048821 & 2 & 10 & 26 & 10 & 11.64 & 5.28 & 14.2392 & $3.2632 \mathrm{E}-05$ & -4.9303 & 72.042133 & 93.0674473 & $11,546.217$ & 23.8342199 & $13,965.92599$ & $1,616,378.31$ \\
\hline GDF & 57.4814459 & 10.0850738 & 2 & 10 & 26 & 10 & 11.64 & 5.28 & 14.2392 & $4.2332 \mathrm{E}-06$ & -4.9303 & 68.5937861 & 42.2830066 & $18,253.9544$ & 34.0607718 & $20,913.57979$ & $1,199,767.99$ \\
\hline GDF & 57.4512264 & 3.01204819 & 2 & 10 & 26 & 10 & 11.64 & 5.28 & 14.2392 & $4.2491 \mathrm{E}-06$ & -4.9303 & 68.4755021 & 20.8944389 & $13,431.3645$ & 24.7918545 & $16,335.49865$ & $888,838.08$ \\
\hline GDF & 57.4638816 & 1.00401606 & 2 & 10 & 26 & 10 & 11.64 & 5.28 & 14.2392 & $4.2424 \mathrm{E}-06$ & -4.9303 & 76.7436615 & 24.1979981 & $10,945.9373$ & 17.9009051 & $13,296.42688$ & $870,809.13$ \\
\hline GDF & 57.4649567 & 0.3014708 & 2 & 10 & 26 & 10 & 11.64 & 5.28 & 14.2392 & $4.2419 \mathrm{E}-06$ & -4.9303 & 74.1551329 & 72.8536287 & 9656.81436 & 13.0450172 & $10,847.88723$ & $1,428,370.58$ \\
\hline GDF & 57.4871958 & 0.10048821 & 2 & 10 & 26 & 10 & 11.64 & 5.28 & 14.2392 & $4.2301 \mathrm{E}-06$ & -4.9303 & 80.9264103 & 23.7750694 & 8707.77945 & 9.64657789 & 9175.653212 & $831,475.77$ \\
\hline GDD & 0.09261823 & 10.040201 & 5 & 21 & 37 & 9 & 11.5 & 2.19 & 14.2392 & 1.9212063 & -4.9303 & 3.52491616 & 915.771162 & $2,612,507.65$ & 6.685383 & $2,765,098.761$ & $32,920,624.02$ \\
\hline GDD & 0.14033187 & 3.01386816 & 5 & 21 & 37 & 9 & 11.5 & 2.19 & 14.2392 & 1.88619087 & -4.9303 & 6.77616546 & 866.917216 & $2,348,150.09$ & 7.73769046 & $2,044,917.579$ & $26,131,567.79$ \\
\hline GDD & 0.14912447 & 1.00502513 & 5 & 21 & 37 & 9 & 11.5 & 2.19 & 14.2392 & 1.87981217 & -4.9303 & 6.57506445 & 797.021499 & $2,127,750.13$ & 10.2600661 & $1,531,215.788$ & $26,003,852.40$ \\
\hline GDD & 0.21741496 & 0.30144998 & 5 & 21 & 37 & 9 & 11.5 & 2.19 & 14.2392 & 1.83103907 & -4.9303 & 6.57623855 & 659.243664 & $1,828,861.76$ & 12.4560758 & $1,086,971.758$ & $25,045,531.43$ \\
\hline GDD & 0.19023634 & 0.10049847 & 5 & 21 & 37 & 9 & 11.5 & 2.19 & 14.2392 & 1.85028796 & -4.9303 & 7.58243214 & 582.819516 & $1,546,907.62$ & 14.8999694 & $794,403.5778$ & $23,055,921.96$ \\
\hline GDD & 9.99615879 & 10.0394831 & 5 & 21 & 37 & 9 & 11.5 & 2.19 & 14.2392 & 0.06151778 & -4.9303 & 5.07239006 & 814.974798 & $1,861,530.22$ & 12.4698703 & $869,757.293$ & $28,680,516.56$ \\
\hline GDD & 9.9931124 & 3.01935013 & 5 & 21 & 37 & 9 & 11.5 & 2.19 & 14.2392 & 0.06157634 & -4.9303 & 11.2039849 & 749.615398 & $1,512,858.41$ & 15.7620458 & $609,942.6473$ & $20,679,108.96$ \\
\hline GDD & 10.001568 & 1.00401606 & 5 & 21 & 37 & 9 & 11.5 & 2.19 & 14.2392 & 0.06141396 & -4.9303 & 14.4533518 & 677.060405 & $1,238,345.39$ & 19.5843992 & $436,899.2$ & $17,971,086.43$ \\
\hline GDD & 9.98754464 & 0.30146212 & 5 & 21 & 37 & 9 & 11.5 & 2.19 & 14.2392 & 0.06168351 & -4.9303 & 19.4556643 & 575.782786 & $926,632.49$ & 24.7817297 & $303,217.3389$ & $14,853,415.54$ \\
\hline GDD & 9.98689178 & 0.10040617 & 5 & 21 & 37 & 9 & 11.5 & 2.19 & 14.2392 & 0.06169609 & -4.9303 & 27.2891121 & 495.211772 & $670,252.844$ & 30.4854157 & $217,043.2266$ & $11,824,486.09$ \\
\hline GDD & 20.1269103 & 10.0413834 & 5 & 21 & 37 & 9 & 11.5 & 2.19 & 14.2392 & 0.00354426 & -4.9303 & 17.6571245 & 597.620284 & $958,620.144$ & 24.4468849 & $294,269.9657$ & $15,769,323.09$ \\
\hline GDD & 20.0560246 & 3.0135854 & 5 & 21 & 37 & 9 & 11.5 & 2.19 & 14.2392 & 0.00360858 & -4.9303 & 25.8690868 & 483.572582 & $665,922.301$ & 30.4486721 & $205,556.777$ & $12,093,283.03$ \\
\hline GDD & 20.1064456 & 1.00401606 & 5 & 21 & 37 & 9 & 11.5 & 2.19 & 14.2392 & 0.0035627 & -4.9303 & 31.1181391 & 370.65869 & $437,246.323$ & 37.7468459 & $147,282.0775$ & $9,961,122.23$ \\
\hline GDD & 20.0685226 & 0.30147077 & 5 & 21 & 37 & 9 & 11.5 & 2.19 & 14.2392 & 0.00359715 & -4.9303 & 36.654363 & 259.66188 & $248,631.576$ & 45.4172653 & $104,202.5862$ & $7,939,936.36$ \\
\hline GDD & 20.0976543 & 0.10049645 & 5 & 21 & 37 & 9 & 11.5 & 2.19 & 14.2392 & 0.00357066 & -4.9303 & 44.527942 & 224.202282 & $137,255.907$ & 51.5662283 & $76,481.06838$ & $6,621,760.55$ \\
\hline GDD & 30.0799395 & 10.0562082 & 5 & 21 & 37 & 9 & 11.5 & 2.19 & 14.2392 & 0.00035961 & -4.9303 & 35.4616724 & 344.846181 & $371,640.071$ & 41.35833 & $123,927.6984$ & $8,975,302.46$ \\
\hline
\end{tabular}




\section{Continued}

\begin{tabular}{|c|c|c|c|c|c|c|c|c|c|c|c|c|c|c|c|c|c|}
\hline GDD & 30.0560471 & 3.02306788 & 5 & 21 & 37 & 9 & 11.5 & 2.19 & 14.2392 & 0.0003614 & -4.9303 & 44.5945339 & 220.554419 & $204,470.748$ & 48.4594628 & $88,137.71521$ & $6,573,690.91$ \\
\hline GDD & 30.0144695 & 1.00401606 & 5 & 21 & 37 & 9 & 11.5 & 2.19 & 14.2392 & 0.00036454 & -4.9303 & 50.5693758 & 123.808965 & $108,713.428$ & 54.2458142 & $65,473.36049$ & $4,795,309.25$ \\
\hline GDD & 30.0015039 & 0.30148487 & 5 & 21 & 37 & 9 & 11.5 & 2.19 & 14.2392 & 0.00036553 & -4.9303 & 53.9316614 & 42.7473578 & $50,611.4689$ & 58.3600607 & $48,077.73687$ & $2,918,352.87$ \\
\hline GDD & 30.0455527 & 0.10049646 & 5 & 21 & 37 & 9 & 11.5 & 2.19 & 14.2392 & 0.00036219 & -4.9303 & 58.4161492 & 60.0953107 & $25,125.303$ & 60.3199869 & $36,803.41605$ & $3,187,840.58$ \\
\hline GDD & 40.1621228 & 10.0510663 & 5 & 21 & 37 & 9 & 11.5 & 2.19 & 14.2392 & $5.3505 \mathrm{E}-05$ & -4.9303 & 53.5109793 & 123.645124 & $100,024.045$ & 56.4833308 & $63,472.97614$ & $4,605,498.16$ \\
\hline GDD & 40.1058896 & 3.02540539 & 5 & 21 & 37 & 9 & 11.5 & 2.19 & 14.2392 & $5.4023 \mathrm{E}-05$ & -4.9303 & 61.5155706 & 47.5308852 & $47,101.7243$ & 58.4891146 & $46,829.21905$ & $2,772,149.95$ \\
\hline GDD & 40.0614253 & 1.00401606 & 5 & 21 & 37 & 9 & 11.5 & 2.19 & 14.2392 & $5.4437 \mathrm{E}-05$ & -4.9303 & 68.0150073 & 22.2557755 & $23,405.1575$ & 57.488496 & $36,050.52238$ & $1,845,058.59$ \\
\hline GDD & 40.1875911 & 0.30148377 & 5 & 21 & 37 & 9 & 11.5 & 2.19 & 14.2392 & $5.3272 \mathrm{E}-05$ & -4.9303 & 68.2770982 & 19.3103215 & $11,528.4893$ & 53.1389633 & $27,460.01294$ & $1,728,817.20$ \\
\hline GDD & 40.1462034 & 0.1005042 & 5 & 21 & 37 & 9 & 11.5 & 2.19 & 14.2392 & $5.3651 \mathrm{E}-05$ & -4.9303 & 69.3990611 & 71.0473782 & 6694.44604 & 45.945857 & $22,016.46557$ & $3,018,417.88$ \\
\hline GDD & 55.0037626 & 10 & 5 & 21 & 37 & 9 & 11.5 & 2.19 & 14.2392 & $5.8035 \mathrm{E}-06$ & -4.9303 & 68.4946979 & 19.5783849 & $17,445.6221$ & 51.3889644 & $31,999.40215$ & $1,735,157.72$ \\
\hline GDD & 55.0480684 & 2.99864315 & 5 & 21 & 37 & 9 & 11.5 & 2.19 & 14.2392 & $5.7701 \mathrm{E}-06$ & -4.9303 & 70.0896294 & 8.86637576 & $10,189.4389$ & 39.4010067 & $24,718.883$ & $1,209,802.35$ \\
\hline GDD & 55.0171667 & 1.00215363 & 5 & 21 & 37 & 9 & 11.5 & 2.19 & 14.2392 & $5.7934 \mathrm{E}-06$ & -4.9303 & 77.9860066 & 2.99792658 & 7150.0433 & 28.6441023 & $19,989.16559$ & $716,723.87$ \\
\hline GDD & 55.0166963 & 0.30165913 & 5 & 21 & 37 & 9 & 11.5 & 2.19 & 14.2392 & $5.7937 \mathrm{E}-06$ & -4.9303 & 75.2791189 & 0.78140181 & 5668.73067 & 20.4529994 & $16,170.53133$ & $445,922.34$ \\
\hline GDD & 55.0121392 & 0.10048232 & 5 & 21 & 37 & 9 & 11.5 & 2.19 & 14.2392 & $5.7971 \mathrm{E}-06$ & -4.9303 & 79.8477553 & 54.2324205 & 4996.475 & 15.8370262 & $13,578.99085$ & $2,418,652.76$ \\
\hline GDC & 0.413688 & 10.0587111 & 3 & 16 & 37 & 8 & 11.12 & 6.95 & 14.2392 & 1.69815982 & -4.9303 & 3.35372725 & 914.976698 & 1602553.7 & 8.64477279 & $1,405,669.017$ & $13,368,068.27$ \\
\hline GDC & 0.42833745 & 3.01932807 & 3 & 16 & 37 & 8 & 11.12 & 6.95 & 14.2392 & 1.68865936 & -4.9303 & 6.71210876 & 867.222265 & $1,397,263.01$ & 9.92835248 & $1,043,198.016$ & $10,513,479.33$ \\
\hline GDC & 0.45047181 & 1.00519364 & 3 & 16 & 37 & 8 & 11.12 & 6.95 & 14.2392 & 1.67441118 & -4.9303 & 6.64259299 & 799.201025 & $1,225,791.23$ & 11.8725263 & $779,480.3148$ & $10,391,697.82$ \\
\hline GDC & 0.47184475 & 0.3014621 & 3 & 16 & 37 & 8 & 11.12 & 6.95 & 14.2392 & 1.66077363 & -4.9303 & 6.83587437 & 663.77895 & $1,033,222.59$ & 14.1127244 & $557,127.1099$ & $9,910,715.28$ \\
\hline GDC & 0.41513403 & 0.10049241 & 3 & 16 & 37 & 8 & 11.12 & 6.95 & 14.2392 & 1.69721953 & -4.9303 & 8.06798113 & 585.849181 & $848,340.297$ & 16.6902439 & $409,276.4073$ & $9,032,776.65$ \\
\hline GDC & 10.2855913 & 10.050509 & 3 & 16 & 37 & 8 & 11.12 & 6.95 & 14.2392 & 0.05621661 & -4.9303 & 5.30366245 & 810.013418 & $1,017,564.41$ & 15.1125289 & $447,466.1747$ & $11,300,310.27$ \\
\hline GDC & 10.3033375 & 3.01204819 & 3 & 16 & 37 & 8 & 11.12 & 6.95 & 14.2392 & 0.05590785 & -4.9303 & 11.5337137 & 742.715543 & $803,981.642$ & 17.9845141 & $313,203.2882$ & $8,186,666.98$ \\
\hline GDC & 10.2816355 & 1.00536283 & 3 & 16 & 37 & 8 & 11.12 & 6.95 & 14.2392 & 0.05628568 & -4.9303 & 14.8231948 & 669.640912 & $633,980.995$ & 21.5664117 & $225,817.9819$ & $7,124,501.31$ \\
\hline GDC & 10.2379991 & 0.30150323 & 3 & 16 & 37 & 8 & 11.12 & 6.95 & 14.2392 & 0.05705368 & -4.9303 & 19.8496569 & 568.947217 & $464,749.038$ & 25.6830699 & $157,607.3032$ & $5,904,914.80$ \\
\hline GDC & 10.282075 & 0.1004087 & 3 & 16 & 37 & 8 & 11.12 & 6.95 & 14.2392 & 0.05627801 & -4.9303 & 27.8370188 & 488.007791 & $337,945.369$ & 30.6879667 & $112,515.6297$ & $4,700,941.73$ \\
\hline GDC & 20.1638394 & 10.0598564 & 3 & 16 & 37 & 8 & 11.12 & 6.95 & 14.2392 & 0.00351125 & -4.9303 & 17.7165694 & 596.708759 & $490,626.28$ & 26.2231505 & $157,138.7837$ & $6,338,480.22$ \\
\hline GDC & 20.1627364 & 3.01987169 & 3 & 16 & 37 & 8 & 11.12 & 6.95 & 14.2392 & 0.00351223 & -4.9303 & 26.0577972 & 480.547083 & $338,818.216$ & 30.9680776 & $109,322.8881$ & $4,854,077.80$ \\
\hline GDC & 20.1713519 & 1.00603622 & 3 & 16 & 37 & 8 & 11.12 & 6.95 & 14.2392 & 0.00350457 & -4.9303 & 31.2413855 & 368.689935 & $228,511.732$ & 35.4375962 & $78,838.66523$ & $4,013,340.19$ \\
\hline GDC & 20.1535057 & 0.3014394 & 3 & 16 & 37 & 8 & 11.12 & 6.95 & 14.2392 & 0.00352045 & -4.9303 & 36.8058926 & 257.105649 & $141,024.718$ & 39.2608292 & $55,791.05881$ & $3,199,675.59$ \\
\hline GDC & 20.2950439 & 0.10048736 & 3 & 16 & 37 & 8 & 11.12 & 6.95 & 14.2392 & 0.00339661 & -4.9303 & 44.8331561 & 219.370963 & $86,634.3288$ & 41.2130594 & $40,656.22834$ & $2,655,505.58$ \\
\hline GDC & 29.9243066 & 10.0738014 & 3 & 16 & 37 & 8 & 11.12 & 6.95 & 14.2392 & 0.00037146 & -4.9303 & 35.1691143 & 348.726506 & $201,236.85$ & 37.7335585 & $67,612.36305$ & $3,667,285.26$ \\
\hline GDC & 29.9690609 & 3.01204819 & 3 & 16 & 37 & 8 & 11.12 & 6.95 & 14.2392 & 0.00036801 & -4.9303 & 44.4310288 & 222.538337 & $121,528.931$ & 41.4607717 & $47,865.96239$ & $2,685,888.54$ \\
\hline GDC & 29.960934 & 1.00452339 & 3 & 16 & 37 & 8 & 11.12 & 6.95 & 14.2392 & 0.00036863 & -4.9303 & 50.4654753 & 124.771518 & $74,085.4511$ & 42.747014 & $35,579.81012$ & $1,963,138.68$ \\
\hline GDC & 29.9595055 & 0.30146215 & 3 & 16 & 37 & 8 & 11.12 & 6.95 & 14.2392 & 0.00036874 & -4.9303 & 53.862896 & 43.2498118 & $42,563.2884$ & 42.1394833 & $26,154.10862$ & $1,202,611.98$ \\
\hline GDC & 29.9449639 & 0.10041287 & 3 & 16 & 37 & 8 & 11.12 & 6.95 & 14.2392 & 0.00036986 & -4.9303 & 58.2909719 & 60.8299171 & $26,972.2542$ & 39.9091768 & $20,123.09243$ & $1,313,333.01$ \\
\hline GDC & 40.2156972 & 10.0225803 & 3 & 16 & 37 & 8 & 11.12 & 6.95 & 14.2392 & $5.3016 \mathrm{E}-05$ & -4.9303 & 53.5971084 & 122.696772 & $63,518.6652$ & 44.2004393 & $34,238.33166$ & $1,869,514.96$ \\
\hline GDC & 40.1984039 & 3.01572142 & 3 & 16 & 37 & 8 & 11.12 & 6.95 & 14.2392 & $5.3173 \mathrm{E}-05$ & -4.9303 & 61.6436012 & 46.5034933 & $37,408.5496$ & 41.4933069 & $25,266.29303$ & $1,123,652.55$ \\
\hline GDC & 40.2513695 & 1.00755846 & 3 & 16 & 37 & 8 & 11.12 & 6.95 & 14.2392 & $5.2694 \mathrm{E}-05$ & -4.9303 & 68.287478 & 21.6867725 & $24,224.4194$ & 36.4036963 & $19,430.40415$ & $748,548.06$ \\
\hline
\end{tabular}




\section{Continued}

\begin{tabular}{|c|c|c|c|c|c|c|c|c|c|c|c|c|c|c|c|c|c|}
\hline GDC & 40.2258792 & 0.30140161 & 3 & 16 & 37 & 8 & 11.12 & 6.95 & 14.2392 & $5.2924 \mathrm{E}-05$ & -4.9303 & 68.3198447 & 19.5040208 & $16,223.6791$ & 29.5586024 & $14,930.06875$ & $714,655.49$ \\
\hline GDC & 40.2156875 & 0.10048838 & 3 & 16 & 37 & 8 & 11.12 & 6.95 & 14.2392 & $5.3016 \mathrm{E}-05$ & -4.9303 & 69.4637318 & 71.5346614 & $12,577.1199$ & 23.5332957 & $11,975.61113$ & $1,238,387.73$ \\
\hline GDC & 54.921576 & 10.1313891 & 3 & 16 & 37 & 8 & 11.12 & 6.95 & 14.2392 & $5.866 \mathrm{E}-06$ & -4.9303 & 68.4768383 & 19.0597114 & $17,931.6945$ & 30.8788185 & $17,513.15425$ & $706,357.48$ \\
\hline GDC & 54.9237794 & 2.99864315 & 3 & 16 & 37 & 8 & 11.12 & 6.95 & 14.2392 & $5.8643 \mathrm{E}-06$ & -4.9303 & 70.1458993 & 8.32835018 & $13,889.9334$ & 22.4885993 & $13,529.58382$ & $486,705.33$ \\
\hline GDC & 55.0136494 & 1.00502513 & 3 & 16 & 37 & 8 & 11.12 & 6.95 & 14.2392 & $5.796 \mathrm{E}-06$ & -4.9303 & 77.987095 & 3.02592751 & $11,367.6813$ & 16.6300479 & $10,919.08857$ & $298,944.86$ \\
\hline GDC & 54.9460801 & 0.30143197 & 3 & 16 & 37 & 8 & 11.12 & 6.95 & 14.2392 & $5.8472 \mathrm{E}-06$ & -4.9303 & 75.3003758 & 2.38249516 & $10,217.637$ & 11.869553 & 8856.76205 & $278,988.37$ \\
\hline GDC & 54.9280078 & 0.10051262 & 3 & 16 & 37 & 8 & 11.12 & 6.95 & 14.2392 & $5.861 \mathrm{E}-06$ & -4.9303 & 79.8077743 & 56.2439923 & 9726.59434 & 10.5417338 & 7448.891435 & $1,008,363.48$ \\
\hline BDD & 1 & 10.04 & 1.75 & 14.7 & 40.25 & 6.5 & 12.25 & 5.05 & 14.2392 & 1.35851344 & -4.9303 & 3.0837 & 913.039714 & $1,647,780$ & 8.02 & $1,561,518.133$ & $18,357,623.04$ \\
\hline BDD & 1.1 & 3.02 & 1.75 & 14.7 & 40.25 & 6.5 & 12.25 & 5.05 & 14.2392 & 1.30814785 & -4.9303 & 6.613727 & 866.850598 & $1,426,510$ & 9.31 & $1,143,403.492$ & $14,156,832.83$ \\
\hline BDD & 1 & 1 & 1.75 & 14.7 & 40.25 & 6.5 & 12.25 & 5.05 & 14.2392 & 1.35851344 & -4.9303 & 6.7977 & 801.937017 & $1,280,060$ & 10.2 & $863,970.9689$ & $13,807,263.91$ \\
\hline BDD & 1 & 0.3 & 1.75 & 14.7 & 40.25 & 6.5 & 12.25 & 5.05 & 14.2392 & 1.35851344 & -4.9303 & 7.39 & 671.673136 & $1,112,150$ & 12.15 & $618,175.1918$ & $12,904,372.86$ \\
\hline BDD & 1 & 0.1 & 1.75 & 14.7 & 40.25 & 6.5 & 12.25 & 5.05 & 14.2392 & 1.35851344 & -4.9303 & 9.3234 & 592.235048 & 957,580 & 14.39 & $450,091.6678$ & $11,406,898.96$ \\
\hline BDD & 12.7 & 10.05 & 1.75 & 14.7 & 40.25 & 6.5 & 12.25 & 5.05 & 14.2392 & 0.02706743 & -4.9303 & 7.5705213 & 765.172336 & 977,880 & 14.71 & $408,458.4034$ & $13,127,329.85$ \\
\hline BDD & 12.7 & 3.02 & 1.75 & 14.7 & 40.25 & 6.5 & 12.25 & 5.05 & 14.2392 & 0.02706743 & -4.9303 & 14.391179 & 685.35977 & 793,150 & 17.38 & $285,434.7623$ & $9,726,690.51$ \\
\hline BDD & 12.6 & 1.01 & 1.75 & 14.7 & 40.25 & 6.5 & 12.25 & 5.05 & 14.2392 & 0.02787916 & -4.9303 & 18.1269096 & 603.892422 & 631,040 & 20.26 & $207,520.4688$ & $8,413,874.84$ \\
\hline BDD & 12.6 & 0.3 & 1.75 & 14.7 & 40.25 & 6.5 & 12.25 & 5.05 & 14.2392 & 0.02787916 & -4.9303 & 23.6764464 & 499.090849 & 471,830 & 24.09 & $144,020.4241$ & $6,925,441.55$ \\
\hline BDD & 12.7 & 0.1 & 1.75 & 14.7 & 40.25 & 6.5 & 12.25 & 5.05 & 14.2392 & 0.02706743 & -4.9303 & 32.224044 & 424.790702 & 344,955 & 27.76 & $102,801.2028$ & $5,526,240.46$ \\
\hline BDD & 22.2 & 10.05 & 1.75 & 14.7 & 40.25 & 6.5 & 12.25 & 5.05 & 14.2392 & 0.00211825 & -4.9303 & 21.1003928 & 545.739457 & 518,955 & 23.7 & $155,699.8437$ & $7,563,353.46$ \\
\hline BDD & 22.3 & 3.01 & 1.75 & 14.7 & 40.25 & 6.5 & 12.25 & 5.05 & 14.2392 & 0.00206741 & -4.9303 & 29.925035 & 420.324203 & 372,505 & 27.86 & $107,744.7488$ & $5,750,252.45$ \\
\hline BDD & 22.3 & 1.01 & 1.75 & 14.7 & 40.25 & 6.5 & 12.25 & 5.05 & 14.2392 & 0.00206741 & -4.9303 & 35.3462817 & 305.965075 & 262,595 & 31.29 & $78,427.28837$ & $4,669,952.36$ \\
\hline BDD & 22.3 & 0.3 & 1.75 & 14.7 & 40.25 & 6.5 & 12.25 & 5.05 & 14.2392 & 0.00206741 & -4.9303 & 40.6341028 & 195.672109 & 169,070 & 34.96 & $55,781.59107$ & $3,626,241.97$ \\
\hline BDD & 22.3 & 0.1 & 1.75 & 14.7 & 40.25 & 6.5 & 12.25 & 5.05 & 14.2392 & 0.00206741 & -4.9303 & 47.865324 & 173.27208 & 109,330 & 37.68 & $41,563.70687$ & $3,101,203.24$ \\
\hline BDD & 32.8 & 10.05 & 1.75 & 14.7 & 40.25 & 6.5 & 12.25 & 5.05 & 14.2392 & 0.00020726 & -4.9303 & 40.5582192 & 278.610638 & 219,095 & 34.4 & $66,072.41342$ & $4,141,648.50$ \\
\hline BDD & 32.8 & 3.02 & 1.75 & 14.7 & 40.25 & 6.5 & 12.25 & 5.05 & 14.2392 & 0.00020726 & -4.9303 & 49.65884 & 161.870566 & 137,750 & 37.23 & $47,509.46454$ & $2,944,321.12$ \\
\hline BDD & 32.7 & 1.01 & 1.75 & 14.7 & 40.25 & 6.5 & 12.25 & 5.05 & 14.2392 & 0.0002114 & -4.9303 & 55.6812873 & 81.4580069 & 89,465 & 38.38 & $35,948.70652$ & $2,051,674.99$ \\
\hline BDD & 32.7 & 0.3 & 1.75 & 14.7 & 40.25 & 6.5 & 12.25 & 5.05 & 14.2392 & 0.0002114 & -4.9303 & 58.2176532 & 18.2651164 & 54,665 & 38.1 & $26,709.73795$ & $1,043,830.00$ \\
\hline BDD & 32.8 & 0.1 & 1.75 & 14.7 & 40.25 & 6.5 & 12.25 & 5.05 & 14.2392 & 0.00020726 & -4.9303 & 61.722804 & 47.4131853 & 35,670 & 36.46 & $20,690.87586$ & $1,511,567.66$ \\
\hline BDD & 43.2 & 10.03 & 1.75 & 14.7 & 40.25 & 6.5 & 12.25 & 5.05 & 14.2392 & $3.2264 \mathrm{E}-05$ & -4.9303 & 58.1244848 & 75.1150491 & 76,705 & 40.24 & $35,265.31143$ & $1,922,321.42$ \\
\hline BDD & 43.2 & 3.01 & 1.75 & 14.7 & 40.25 & 6.5 & 12.25 & 5.05 & 14.2392 & $3.2264 \mathrm{E}-05$ & -4.9303 & 65.400904 & 18.9792433 & 47,270 & 38.45 & $26,300.38674$ & $973,582.84$ \\
\hline BDD & 43.2 & 1 & 1.75 & 14.7 & 40.25 & 6.5 & 12.25 & 5.05 & 14.2392 & $3.2264 \mathrm{E}-05$ & -4.9303 & 72.1344408 & 17.3170535 & 31,610 & 34.47 & $20,492.93985$ & $870,204.45$ \\
\hline BDD & 43.2 & 0.3 & 1.75 & 14.7 & 40.25 & 6.5 & 12.25 & 5.05 & 14.2392 & $3.2264 \mathrm{E}-05$ & -4.9303 & 71.3135472 & 36.9143105 & 21,750 & 29.87 & $15,944.8262$ & $1,218,948.48$ \\
\hline BDD & 43.2 & 0.1 & 1.75 & 14.7 & 40.25 & 6.5 & 12.25 & 5.05 & 14.2392 & $3.2264 \mathrm{E}-05$ & -4.9303 & 72.100964 & 93.5823287 & 16,675 & 25.43 & $12,937.05617$ & $1,804,621.20$ \\
\hline BDD & 57.8 & 10.06 & 1.75 & 14.7 & 40.25 & 6.5 & 12.25 & 5.05 & 14.2392 & $4.069 \mathrm{E}-06$ & -4.9303 & 68.5425192 & 46.2261298 & 25,375 & 31.81 & $19,194.89525$ & $1,383,842.61$ \\
\hline BDD & 57.8 & 3.01 & 1.75 & 14.7 & 40.25 & 6.5 & 12.25 & 5.05 & 14.2392 & $4.069 \mathrm{E}-06$ & -4.9303 & 68.15534 & 22.8532315 & 19,430 & 24.41 & $15,013.47004$ & $1,023,530.14$ \\
\hline BDD & 57.8 & 1 & 1.75 & 14.7 & 40.25 & 6.5 & 12.25 & 5.05 & 14.2392 & $4.069 \mathrm{E}-06$ & -4.9303 & 76.4949352 & 29.2917623 & 16,240 & 19.52 & $12,238.66537$ & $1,046,456.91$ \\
\hline BDD & 57.8 & 0.3 & 1.75 & 14.7 & 40.25 & 6.5 & 12.25 & 5.05 & 14.2392 & $4.069 \mathrm{E}-06$ & -4.9303 & 73.9411968 & 85.9452506 & 13,485 & 15.17 & $10,001.86048$ & $1,708,749.65$ \\
\hline BDD & 57.8 & 0.1 & 1.75 & 14.7 & 40.25 & 6.5 & 12.25 & 5.05 & 14.2392 & $4.069 \mathrm{E}-06$ & -4.9303 & 81.049304 & 36.4719264 & 12,615 & 12.53 & 8477.437697 & $1,102,701.27$ \\
\hline
\end{tabular}

